\title{
Distribución vertical del rendimiento y la calidad forrajera en el componente vegetativo de la planta de maíz (Zea mays L.).
}

\section{Luis Ezequiel García Stepien}

\author{
Ingeniero Agrónomo \\ 2007 \\ Universidad Nacional de Lomas de Zamora
}

Tesis para optar al Grado Académico de

Magister en Ciencias Agrarias y Forestales

Mención: Producción Vegetal

La Plata, 2012 


\title{
Comité Consejero
}

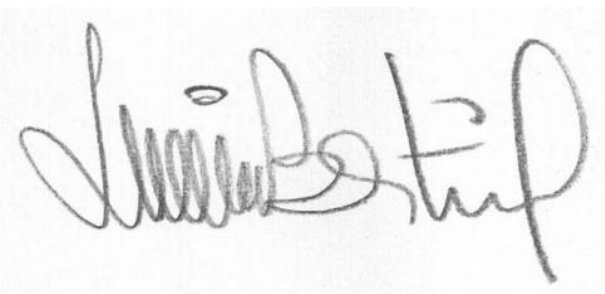

\author{
Director de Tesis \\ Luis Máximo Bertoia \\ Ingeniero Agrónomo (MSc), Dr. \\ Profesor Titular - Cerealicultura \\ Profesor Adjunto - Manejo de Pastutras \\ Facultad de Cs. Agrarias - UNLZ
}

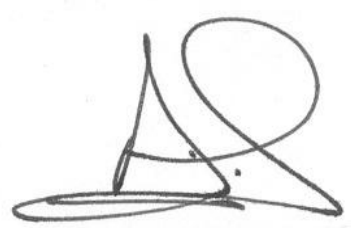

\section{Co-Director de Tesis}

\section{Horacio Acciaressi}

Ingeniero Agrónomo (MSc), Dr.

Profesor Adjunto - Cerealicultura

Facultad de Cs. Agrarias y Forestales - UNLP 


\section{DEDICATORIA:}

\section{A Rocío y a Pía.}




\section{AGRADECIMIENTOS:}

A mis Padres y Hermana, por su apoyo incondicional.

A mis amigos, por estar siempre presentes.

A Salvador, por su incesable motivación.

A Luis, por su guía.

A Marcelo, por sus innumerables consejos.

A María, por su ayuda.

A mis compañeros. 
ÍNDICE GENERAL

Contenido

Página

\begin{tabular}{ll}
\hline & ÍNDICE DE TABLAS \\
& ÍNDICE DE FIGURAS \\
& ACRÓNIMOS \\
& RESUMEN \\
& ABSTRACT \\
I. & Capítulo I. INTRODUCCIÓN GENERAL. \\
I.1 & Presentación del problema. \\
I.2 & Objetivos. \\
I.3 & Hipótesis. \\
I.4 Experimentos realizados. & Capítulo II. PERFIL VERTICAL DE DISTRIBUCIÓN DEL \\
II. & RENDIMIENTO Y LA CALIDAD NUTRICIONAL SOBRE LA \\
& FRACCIÓN VEGETATIVA DE LA PLANTA EN HÍBRIDOS DE \\
& MAÍZ.
\end{tabular}

II.1 Introducción.

II.2 Materiales y Métodos. 8

II.2.1. Genotipos. 8

II.2.2. Manejo del cultivo y diseño experimental. 8

$\begin{array}{lll}\text { II.2.3. Mediciones. } & 10\end{array}$

II.2.4. Análisis estadístico. $\quad 11$

$\begin{array}{lll}\text { II.3 Resultados y Discusión. } & 13\end{array}$

$\begin{array}{lll}\text { II.4 Conclusiones. } & 27\end{array}$

III. Capítulo III. RELACIÓN ENTRE EL ÍNDICE DE ESPIGA Y LA CALIDAD FORRAJERA DE LA FRACCIÓN VEGETATIVA EN HÍBRIDOS CON DISTINTO ORIGÉN GENÉTICO.

$\begin{array}{lll}\text { III.1 Introducción. } & 29\end{array}$

III.2 Materiales y Métodos. 31

III.2.1. Datos experimentales. 31

III.2.2. Mediciones. 31

III.2.3. Análisis estadístico. 32

III.3 Resultados y Discusión 32

$\begin{array}{lll}\text { III.4 Conclusiones. } & 36\end{array}$

Luis Ezequiel García Stepien. Tesis de Magister Scientiae en Ciencias Agrarias. Mención en Producción Vegetal. Facultad de Ciencias Agrarias y Forestales. UNLP. 
IV. Capítulo IV. LA ALTURA DE CORTE: EFECTO SOBRE LA APTITUD FORRAJERA Y EL RENDIMIENTO DEL MATERIAL A ENSILAR.

IV.1 Introducción.

IV.2 Materiales y Métodos 40

IV.2.1. Datos experimentales. 40

IV.2.2. Mediciones. $\quad 40$

$\begin{array}{lll}\text { IV.2.3. Análisis estadístico. } & 41\end{array}$

$\begin{array}{lll}\text { IV.3 Resultados y Discusión } & 42\end{array}$

$\begin{array}{lll}\text { IV.5 Conclusiones } & 47\end{array}$

V Capítulo V. CONCLUSIONES GENERALES 48

VI. Capítulo VI. INVESTIGACIONES FUTURAS. 50

BIBLIOGRAFÍA 51

$\begin{array}{ll}\text { ANEXO } & 59\end{array}$ 


\section{ÍNDICE DE TABLAS}

Contenido

1. Caracterización de los materiales evaluados según obtentor.

2. Temperatura media del aire del periodo siembra - R1.

3. Caracterización morfológica y fenológica de los seis híbridos de maíz.

4. Análisis de varianza para $\triangle \mathrm{RMSb}\left(\mathrm{kg} \% \mathrm{AR}^{-1}\right)$ empleando un modelo mixto de 6 híbridos comerciales (efecto fijo), en 4 Ambientes (efecto aleatorio).

5. Medias de $\triangle \mathrm{RMSb}\left(\mathrm{kg} \% \mathrm{AR}^{-1}\right)$, para los 4 Ambientes evaluados.

6. Análisis de varianza para $\triangle \mathrm{RMSs}\left(\mathrm{kg} \% \mathrm{AR}^{-1}\right)$ empleando un modelo mixto de 6 híbridos comerciales (efecto fijo), en 4 Ambientes (efecto aleatorio).

7. Medias de $\triangle \mathrm{RMSs}\left(\mathrm{kg} \% \mathrm{AR}^{-1}\right)$, para los 4 Ambientes evaluados.

8. Análisis de varianza para $\Delta \% \mathrm{MSb}\left(\% \mathrm{MS} \% \mathrm{AR}^{-1}\right)$ empleando un modelo mixto de 6 híbridos comerciales (efecto fijo), en 4 Ambientes (efecto aleatorio).

9. Medias de $\Delta \% \mathrm{MSb}\left(\% \mathrm{MS} \% \mathrm{AR}^{-1}\right)$, para los 4 Ambientes evaluados.

10. Análisis de varianza para $\Delta \% \mathrm{MSs}\left(\mathrm{kg}_{0} \%\right.$ altura $\left.{ }^{-1}\right)$ empleando un 23 modelo mixto de 6 híbridos comerciales (efecto fijo), en 4 Ambientes (efecto aleatorio).

11. Análisis de varianza para $\Delta \mathrm{Divb}\left(\% \mathrm{D} i v \% \mathrm{AR}^{-1}\right)$ empleando un 24 modelo mixto de 6 híbridos comerciales (efecto fijo), en 4 Ambientes (efecto aleatorio).

12. Medias de $\Delta \mathrm{D} i v \mathrm{~b}\left(\% \mathrm{D} i v \% \mathrm{AR}^{-1}\right)$, para los 4 Ambientes evaluados. 25

13. Medias de $\Delta$ Divb (kg \%altura ${ }^{-1}$ ), para los 6 Híbridos evaluados. 26

14. Análisis de varianza para $\Delta$ Divs (\% Div \%altura $\left.{ }^{-1}\right)$ empleando un 27 modelo mixto de 6 híbridos comerciales (efecto fijo), en 4 ambientes (efecto aleatorio).

15. Análisis de correlación entre en Índice de Cosecha y la Digestibilidad in vitro de la fracción vegetativa de 6 híbridos, promedio de 4 ambientes.

16. Efecto e la Altura de corte sobre la aptitud forrajera.

17. Medias de las tres alturas de corte para las variables: Índice de 43 
Cosecha de Espiga (IC), Contenido de Materia Seca de planta completa (\%MSpc), Digestibilidad in vitro de planta completa (Divpc), de seis híbridos en los cuatro ambientes.

18. Aporte del IC a cada una de las Digestibilidades de la planta de Maíz. 44 Matriz de correlaciones entre: Divpc; Divc+h e IC.

19. Medias de las variables: Índice de Cosecha (IC), Rendimiento en 46 Materia Seca de planta completa (RMSpc), Digestibilidad in vitro de planta completa (Divpc), rendimiento en materia seca digestible de planta completa (RMSDpc) de seis híbridos para los cuatro ambientes. 


\section{ÍNDICE DE FIGURAS}

Contenido

Página

1. $\quad$ Temperatura media del aire medida en ${ }^{\circ} \mathrm{C}$.

13

2. Precipitaciones mensuales ( $\mathrm{mm} / \mathrm{mes})$.

3. Distribución vertical del RMS $\left(\mathrm{kg} \mathrm{ha}^{-1}\right)$ en la fracción vegetativa de la planta de maíz. Promedio de 6 híbridos comerciales en 4 Ambientes.

4. Distribución vertical del contenido de materia seca (\%) en la fracción 21 vegetativa de la planta de maíz. Promedio de 6 híbridos comerciales en 4 Ambientes.

5. Distribución vertical de la Digestibilidad in vitro (\%) de la fracción 24 vegetativa de la planta de maíz, de 6 híbridos comerciales en 4 ambientes.

6. Índice de Cosecha vs. Calidad de la fracción vegetativa.

7. Correlación entre en índice de Cosecha (IC) y la Digestibilidad in 34 vitro de la fracción vegetativa de la planta de maíz. Valores de seis híbridos en 4 ambientes con 3 repeticiones. 


\section{ACRÓNIMOS}

\begin{tabular}{|c|c|}
\hline Acrónimo & Referencia \\
\hline$\% \mathrm{MS}$ & Contenido de materia seca. \\
\hline$\% \mathrm{MSc}+\mathrm{h}$ & Contenido de materia seca de caña + hojas. \\
\hline$\% \mathrm{Mse}$ & Contenido de materia seca de espiga completa. \\
\hline$\% \mathrm{MSpc}$ & Contenido de materia seca de planta completa. \\
\hline${ }^{\circ} \mathrm{C}$ & Grados Centígrados. \\
\hline A & Ambiente. \\
\hline ANVA & Análisis de Varianza. \\
\hline $\mathrm{AR} \%$ & Altura Relativa. \\
\hline $\mathrm{C}$ & Cosecha. \\
\hline $\mathrm{cm}$ & Centímetro. \\
\hline Div & Digestibilidad in vitro. \\
\hline Divc $+h$ & Digestibilidad in vitro de caña + hojas \\
\hline Dive & Digestibilidad in vitro de espiga completa. \\
\hline Divpc & Digestibilidad in vitro de planta completa. \\
\hline ha & Hectárea. \\
\hline IE & Índice de Espiga. \\
\hline $\mathrm{kg}$ & Kilogramo. \\
\hline 1 & Litro. \\
\hline $\mathrm{m}$ & Metro. \\
\hline $\mathrm{Mg}$ & Megagramo. \\
\hline $\mathrm{mm}$ & Milímetro. \\
\hline MS & Materia seca. \\
\hline NIRS & Near infrared reflectance spectroscopy. \\
\hline $\mathrm{O}$ & Oeste. \\
\hline $\mathrm{p}$ & $\mathrm{p}$ value. \\
\hline R1 & Floración Femenina (Ritchie y Hanway, 1982). \\
\hline R5 & Grano Dentado. (Ritchie y Hanway, 1982). \\
\hline RMS & Rendimiento en materia seca. \\
\hline$R M S c+h$ & Rendimiento en materia seca de caña + hojas. \\
\hline $\mathrm{S}$ & Sur. \\
\hline V3 & Tercer hoja expandida. (Ritchie y Hanway, 1982). \\
\hline X0 & Altura de inserción de la espiga. \\
\hline$\Delta$ divb & Tasa de variación de la Divc+h por debajo de $\mathrm{X}_{0}$. \\
\hline$\Delta$ Divs & Tasa de variación de la Divc+h por arriba de $\mathrm{X}_{0}$. \\
\hline$\Delta \mathrm{MSb}$ & Tasa de variación del $\% \mathrm{MSc}+\mathrm{h}$ por debajo de $\mathrm{X}_{0}$. \\
\hline$\Delta \mathrm{MSs}$ & Tasa de variación del $\% \mathrm{MSc}+\mathrm{h}$ por arriba de $\mathrm{X}_{0}$. \\
\hline$\Delta \mathrm{RMSb}$ & Tasa de variación del RMSc+h por debajo de $\mathrm{X}_{0}$. \\
\hline$\Delta \mathrm{RMSs}$ & Tasa de variación del $\mathrm{RMSc}+\mathrm{h}$ por arriba de $\mathrm{X}_{0}$. \\
\hline
\end{tabular}




\section{Resumen}

El maíz, pese a su importancia indiscutible en la alimentación animal, ha sido estudiado y mejorado atendiendo principalmente a su componente granífero. La fracción vegetativa (caña + hojas) fue considerada sólo como un medio para maximizar el rendimiento de grano sin poner énfasis en su calidad nutricional. Este concepto antiguo de maíz forrajero fue fuertemente cuestionado, ya que el ensilado se realiza con la planta entera más que con el grano. Algunos autores plantean que la selección para rendimiento en grano y resistencia al vuelco puede disminuir la calidad del forraje. En los programas de mejoramiento para genotipos forrajeros el componente vegetativo es una fuente importante de variabilidad genética en pro de una mejora de la calidad nutricional. La fracción vegetativa de la planta de maíz genera el 50\% - 70\% del rendimiento en Materia Seca (MS) del material a ensilar, dependiendo del genotipo, del ambiente y del manejo del cultivo. El aumento de la altura de corte modifica la composición de la planta de maíz, produciendo un incremento en la relación grano/caña+hojas. Los objetivos de nuestro estudio fueron: i. Determinar los perfiles de la distribución vertical del rendimiento en materia seca de la fracción vegetativa y cuantificar las potenciales diferencias producidas por efectos genético- ambientales en distintos híbridos. ii. Cuantificar y comparar potenciales diferencias en los perfiles de distribución vertical de la calidad forrajera de la fracción vegetativa producidas por efectos genéticos-ambientales. iii. Determinar el grado de asociación entre el incremento del Índice de Espiga y la modificación de la calidad nutricional de la fracción vegetativa en híbridos con distinto fondo genético. iv. Determinar las potenciales variaciones que se producirían por efecto de cortes a diferentes alturas en la materia seca y la calidad forrajera del material a ensilar. Seis híbridos comerciales con distinta fondo genético fueron evaluados en 4 ambientes (Localidad $\times$ fecha de siembra) en un diseño de bloques completos aleatorizados con tres repeticiones. Se determinó que atributos tales como los perfiles de distribución vertical del rendimiento $\left(\mathrm{kg} \mathrm{MS} \mathrm{ha}^{-1}\right)$ y la calidad nutricional de la fracción vegetativa, así como también la relación entre el IE y la Divc+h, son fuentes de variabilidad a tener en cuenta en planes de mejoramiento destinados a obtener materiales sileros. También se concluyó sobre el potencial efecto de la altura de corte sobre la aptitud forrajera del material a ensilar, la variabilidad entre híbridos, entre ambientes y su respectiva interacción.

Palabras clave: Silaje, maíz, calidad forrajera, altura de corte. 


\section{Abstract}

The maize, despite its undeniable importance in animal feed has been studied and improved primarily grain yield. The stover was considered only as a tool to maximize grain yield without take into account its nutritional quality. This old concept of forage maize was strongly questioned, because silage is done with the whole plant rather than the grain. Some authors suggest that selection for grain yield and resistance to lodging can decrease forage quality. In breeding programs for forage, stover is an important source of genetic variability with target to improve nutritional quality. Stover generates $50 \%-70 \%$ of dry matter yield (DMY) of silage material, depending on the genotype, environment and crop management. Increasing the cutting height modifies the composition of the corn plant, producing an increase of the ratio grain / stover. The objectives of this study were: i. To determine the profiles of the vertical distribution of dry matter yield of stover and to quantify the potential differences caused by genetic and environmental effects in different hybrids. ii. To quantify and compare potential differences in the profiles of vertical distribution of the quality of vegetative fraction produced by genetic and environmental effects. iii. To determine the degree of association between increased Ear Index (EI) and modification of the nutritional quality of stover in hybrids with different genetic background. iv. Identify potential changes that would occur as a result of cuts at different heights in the dry matter and forage quality of the material to be ensiled. Six commercial hybrids with different genetic background were tested in 4 settings (Location $\times$ planting date) in a randomized complete block design with three replications. It was determined that attributes such as vertical distribution profiles of yield (DM ha $\left.{ }^{-1}\right)$ and stover nutritional quality, as well as the relationship between EI and Divstover, are sources of variability to consider on improvement plans for obtaining forage hybrids. Also conclude on the potencial effect of cutting height on the ability of the material to be ensiled forage, the variability between hybrids and their respective environment interactions.

Keywords: silage, corn, forage quality, cutting height. 


\section{Capítulo I. INTRODUCCIÓN GENERAL.}

\section{I.1. PRESENTACIÓN DEL PROBLEMA.}

En la actualidad se evidencia un desplazamiento de la actividad ganadera hacia zonas marginales conjuntamente con una reducción de la superficie destinada a la producción de forrajes. Frente a este panorama, el productor ganadero debe recurrir a importantes inversiones destinadas a la generación de forrajes que aporten elevados rendimientos por unidad de superficie y excelente calidad nutricional. En el contexto presente y futuro de una intensificación ganadera, el cultivo de maíz para silaje cobra relevancia.

Este cultivo, cuando se lo destina a la producción de silaje, presenta varias cualidades que lo aventajan frente a otros cultivos factibles de ensilar. Entre las mismas merece destacarse el rendimiento en materia seca (RMS) por unidad de superficie, el alto valor nutritivo y elevado contenido de azúcares solubles fermentables (Allen et al., 2003). Estas propiedades permiten que sea utilizado para lograr un adecuado crecimiento y terminación en bovinos para carne y alta producción láctea en tambos (Allen et al., 2003). Por estas razones, el uso de maíz como recurso forrajero, tanto como planta en pie o ensilado es una práctica común en países de agricultura avanzada, ya que permite satisfacer los requerimientos animales en épocas en las que la estacionalidad de la producción forrajera no los cubren (Brero, 1974 y 1979).

Mientras que en los años '70 el área sembrada de maíz era cercana a 4 millones de hectáreas, la aparición de la soja redujo la superficie maicera a casi 3 millones de hectáreas durante las dos décadas pasadas. Actualmente dicha superficie alcanzó unas 3,7 millones de hectáreas en la campaña 2010/11 (SAGPyA, 2011).

Pese a su importancia en la alimentación animal, la planta de maíz ha sido estudiada y mejorada atendiendo preferentemente su productividad en grano (Barrière et al., 2005). La escasa información bibliográfica disponible demuestra que la fracción vegetativa (caña + hojas) fue considerada sólo como un medio para maximizar el rendimiento de grano sin poner énfasis en su calidad nutricional (Dhillon et al., 1990; Pedersen, 1996; Barrière et $a l .$, 2005). De este modo, se incrementó el contenido energético del ensilaje, ya que la espiga constituye el principal aporte al total de nutrientes digestibles del maíz. Por esta razón, por un extenso período se considero al mejor híbrido granífero como el mejor forrajero (Nevens, 1933; Nevens y Dungan, 1942). Este concepto antiguo de maíz forrajero es muy cuestionable, ya que el ensilado se realiza con la planta entera y no sólo con el

Luis Ezequiel García Stepien. Tesis de Magister Scientiae en Ciencias Agrarias. Mención en Producción Vegetal. 
grano (Dhillon et al., 1990). Roth et al. (1970), Gunn (1975) y Twumasi-Afriye y Hunter (1982) plantearon que la selección para rendimiento en grano y resistencia al vuelco puede disminuir la calidad del forraje.

La digestibilidad de la porción vegetativa varía de acuerdo al contenido de pared celular, a la cantidad y composición química de la lignina (principal factor de pérdida de calidad en las plantas) y a su distribución en la pared secundaria de las células vegetales. Estas características varían entre los estratos inferiores y superiores de la planta de maíz (Rimieri et al., 2001; Alessandro, 2002; Alessandro et al. , 2005). También existe variabilidad por efecto del genotipo, estado de madurez a la cosecha y del ambiente (Allen et al., 2003; Barrière et al., 2005).

Existen genotipos de maíz que presentan un retraso de la senescencia foliar al ser comparados con un genotipo de referencia, a este rasgo se lo denomina Stay green, (Thomas y Howarth, 2000). Bosch et al. (1989), encontraron que aquellos híbridos de maíz con destino forrajero que presentaban el rasgo Stay green podían aventajar a sus competidores por presentar un mayor período de picado y por una menor pérdida de digestibilidad de la materia seca de caña + hojas (Bosch et al.1990), siendo estas dos características de relevancia para un genotipo con destino forrajero. Pedersen, (1996), resaltó el rol del componente vegetativo de la planta de maíz, como una fuente importante de variabilidad genética para el mejoramiento de la calidad nutricional los programas de mejoramiento para genotipos forrajeros.

Por tal motivo, la distribución vertical del rendimiento y la calidad del componente vegetativo son dos variables que deberían ser consideradas para la futura selección de genotipos de maíz destinados a la producción forrajera.

El ideotipo de maíz forrajero debería generar altos rendimientos de materia seca de excelente calidad, que podrían alcanzarse mediante el empleo de genotipos de mayor tamaño, utilizando densidades de siembra similares o menores que las usadas en los híbridos para grano (rendimiento vertical) o bien, mediante el empleo de genotipos de arquitectura más baja y compacta, capaces de tolerar altas densidades sin resignar rendimiento ni calidad (rendimiento horizontal) (Bertoia, 2000). Ciertas características en el maíz para silaje, como la digestibilidad, son escasamente modificadas por el ambiente, 
mientras que el rendimiento está fuertemente condicionado por la expresión ambiental (Bertoia, 2000, 2012).

Gravellier (1986), propone que un híbrido para silaje no requiere una fuerte translocación desde la caña hacia el grano, como en los híbridos graníferos, sino que la misma debería transformarse en un segundo depósito de energía altamente digestible, mientras Zimmer y Wermke (1986), plantearon la existencia de variabilidad genética para la translocación de asimilados desde la caña hacia la espiga. Estas observaciones, sostienen las bases para la búsqueda de variabilidad genética del grado de asociación entre el Índice de Espiga [IE = peso seco de espiga completa/peso seco de planta completa] (Fairey, 1980) y la calidad nutricional de la fracción vegetativa.

La regulación de la altura de corte es una práctica alternativa de bajo costo y alto impacto en el rendimiento y la calidad del material a ensilar, en función de exigencias de calidad en sistemas intensivos de alta producción. El aumento en la calidad del silaje se traduce en una mayor producción animal (1 de leche ó $\mathrm{kg}$ de carne/Mg de MS de forraje y 1 de leche ó kg de carne/ha) (González Castañeda et al., 2005; Neylon y Kung, 2003). Lewis et al. (2004), encontraron variabilidad genética para la respuesta de la calidad nutricional a variaciones en la altura de corte, ya que estos aumentos en calidad pueden traducirse o no en aumentos en la producción láctea o cárnica, debido a que puede ocurrir que no logren compensar sus mermas en el rendimiento (RMS/ha). No sólo debemos preocuparnos por el rendimiento y la calidad, sino también de la aptitud técnica del forraje (Struik y Deinum, 1990), siendo esta la capacidad que tiene un vegetal para generar forraje de calidad mediante el proceso de ensilaje.

En este contexto, cobra valor el conocimiento de la distribución vertical del rendimiento ( $\mathrm{kg} \mathrm{MS} \mathrm{ha}^{-1}$ ) y la calidad de la planta completa de maíz. Como asimismo, se incrementa la importancia de conocer la variabilidad entre híbridos, ambientes y su respectiva interacción para estos caracteres; así como también la relación entre el IE y la calidad nutricional de la fracción vegetativa, todo este conocimiento se podrá relacionar con el efecto de la altura de corte para conseguir una aptitud forrajera diferencial del material a ensilar. 


\section{I.2. OBJETIVOS.}

1. - Determinar los perfiles de la distribución vertical del rendimiento en materia seca de la fracción vegetativa y cuantificar las potenciales diferencias producidas por efectos genético- ambientales en híbridos con distinto fondo genético.

2.- Cuantificar y comparar en híbridos con distinto fondo genético las potenciales diferencias en los perfiles de distribución vertical de la calidad forrajera de la fracción vegetativa producidas por efectos genéticos-ambientales.

3.- Determinar el grado de asociación entre el incremento del IE y la calidad nutricional de la fracción vegetativa en híbridos con distinto fondo genético.

4.- Determinar las potenciales variaciones que se producirían por efecto de cortes a diferentes alturas en la materia seca y la calidad forrajera del material a ensilar.

\section{I.3. HIPÓTESIS.}

A.- El rendimiento en materia seca de la fracción vegetativa presenta valores máximos en la base de la planta, disminuyendo hacia la sección apical de la misma.

B.- El aporte de los estratos de la fracción vegetativa a la calidad nutricional sigue una distribución centrípeta con valores máximos en la fracción que porta a la espiga.

C.- El incremento del índice de cosecha afecta en forma inversa la calidad forrajera de la fracción vegetativa en diferentes híbridos de maíz de diverso fondo genético.

D.- Las pérdidas de rendimiento producidas por elevar la altura de corte son compensadas con una mejor aptitud técnica en aquellos híbridos que presentan un elevado grado de Stay green. 


\section{I.4. Experimentos realizados}

Para cumplir con los objetivos propuestos y poner a prueba las hipótesis planteadas se llevaron a cabo una serie de mediciones sobre la base de un mismo ensayo repetido en cuatro ambientes (Localidad $\times$ fecha de siembra). En el Capítulo II, se caracterizó a un grupo de 6 híbridos simples determinando sus perfiles de distribución vertical del rendimiento y calidad forrajera. En dicho capítulo se pusieron a prueba las hipótesis A y B y se cumplieron con los objetivos 1 y 2. En el Capítulo III, se analizó la relación entre el IE y la calidad forrajera sobre la base de los experimentos descriptos en el capítulo II. Se cumplió con el objetivo 3 y se puso a prueba la hipótesis C. Por último, en el Capítulo IV, se analizó la incidencia de la regulación de la altura de corte sobre el material a ensilar. Aquí se evaluaron los mismos 6 genotipos, se cumplió con el objetivo 4 y se puso a prueba la hipótesis D. 


\section{Capítulo II. DISTRIBUCIÓN VERTICAL DEL RENDIMIENTO Y LA CALIDAD NUTRICIONAL SOBRE LA FRACCIÓN VEGETATIVA DE LA PLANTA EN HÍBRIDOS DE MAÍZ.}

\section{II.1. INTRODUCCIÓN.}

La senescencia foliar de la planta de maíz es un proceso condicionado genéticamente (Borrás et al., 2003), donde las hojas posicionadas cerca de la espiga presentan una mayor duración de la actividad fotosintética que aquellas ubicadas por encima y por debajo de la misma (Thiagarajah et al., 1981). La senescencia foliar progresa desde las hojas más viejas ubicadas en la base de la planta hacia arriba, y luego cuando el período de llenado avanza, las hojas superiores comienzan a senescer en sentido basípeto (Valentinuz y Tollenaar, 2004). Esta declinación del área foliar verde durante el llenado de granos presenta dos períodos bien diferenciados. El primero muestra una leve disminución lineal hasta la mitad del período de llenado, seguido de una rápida pérdida del área foliar verde (Valentinuz y Tollenaar, 2004). Tal comportamiento se ve atenuado en los híbridos con el rasgo Stay green, los cuales presentan una senescencia foliar retrasada con respecto a un híbrido de referencia (Thomas y Howarth, 2000). Esta propiedad les permite lograr una mayor actividad fotosintética durante más tiempo, con lo que se consigue aumentar la relación fuente-destino durante el llenado de grano (Tollenaar et al., 1997; Valentinuz y Tollenaar, 2004). Sin embargo, algunos autores (Edmeades et al., 1997) encontraron falta de asociación entre senescencia foliar retardada y rendimiento en condiciones de estrés hídrico. Esto plantea la posibilidad de que la retención del contenido de clorofila de las hojas no siempre se encuentre asociado a un mantenimiento de su capacidad fotosintética (Thomas y Howarth, 2000; Delard Rodríguez, 2006). Esta propiedad ha permitido agrupar las diferentes formas de senescencia foliar retrasada, en dos principales grupos. El primero es un retraso de la senescencia foliar visual (cosmético o no funcional) que ocurre en aquellos casos en que existe un retraso en la degradación de clorofila, sin contribución neta a la capacidad de fijación de carbono (Thomas y Howarth, 2000). En el segundo caso, el retraso se produce en la degradación de la clorofila y se encuentra acompañado por una mantención de la capacidad fotosintética (Thomas y Howarth, 2000). Puede apreciarse que al avanzar la senectud de la fracción vegetativa decrece su calidad forrajera (Darby y Lauer, 2002). El contenido de proteínas se ve disminuido, se expresa un aumento lineal de la fibra detergente ácido (FDA) y la fibra detergente neutro (FDN), y disminuye la 
digestibilidad in vitro (Darby y Lauer, 2002). Tal respuesta puede estar dada por un incremento en la lignificación de la pared celular (Lewis, et. al, 2004). Existen diferencias en la calidad y en el aporte al rendimiento entre estrato inferior y superior a la espiga de la fracción vegetativa. El estrato inferior es el de mayor contenido de FDA, menor degradabilidad potencial y mayor rendimiento (King et al., 1971; Alesandro, 2002).

Estas variaciones en el grado de Stay green y entre los genotipos producirían diferencias en el contenido de materia seca, rendimiento y calidad forrajera. Esto último, repercutiría directamente en decisiones relacionadas con el manejo del cultivo (regulación de la altura de corte o momento de picado) y con la selección de genotipos por su aptitud forrajera.

\section{Objetivos.}

1. - Determinar los perfiles de la distribución vertical del rendimiento en materia seca de la fracción vegetativa y cuantificar las potenciales diferencias producidas por efectos genético- ambientales en híbridos con distinto fondo genético.

2.- Cuantificar y comparar en híbridos con distinto fondo genético las potenciales diferencias en los perfiles de distribución vertical de la calidad forrajera de la fracción vegetativa producidas por efectos genéticos-ambientales.

\section{Hipótesis.}

A.- El rendimiento en materia seca de la fracción vegetativa presenta valores máximos en la base de la planta, disminuyendo hacia la sección apical de la misma.

B.- El aporte de los estratos de la fracción vegetativa a la calidad nutricional sigue una distribución centrípeta con valores máximos en la fracción que porta a la espiga. 


\section{II.2. MATERIALES Y MÉTODOS.}

\section{II.2.1. Genotipos.}

Se evaluaron seis híbridos simples comerciales (Tabla 1) representantes de diferentes patrones heteróticos y que muestran diferencias en el grado de Stay green, de acuerdo a la información suministrada por las empresas semilleras, que proveyeron los híbridos. Las mismas utilizaron el criterio establecido por Thomas y Howart (2000), quienes definieron la senescencia foliar retrasada como una comparación con un genotipo estándar de referencia. A su vez se buscó similitud en la duración de su ciclo para uniformar las condiciones ambientales a los que se sometieron a los genotipos.

Tabla1. Caracterización de los genotipos evaluados según obtentor.

\begin{tabular}{ccccc}
\hline Empresa & Híbrido & Ciclo* & Madurez Relativa & Grado de Stay green \\
\hline Pioneer & $31 \mathrm{~B} 18$ & 777 & 119 & Alto \\
Pioneer & $30 \mathrm{R} 76$ & 766 & 118 & Medio \\
Pioneer & $31 \mathrm{~A} 25$ & 777 & 117 & Bajo \\
Monsanto & DK 747 MG & 685 & 124 & Alto \\
Monsanto & AW 190 MG & 647 & 121 & Medio \\
Monsanto & DK 670 MG & 655 & 117 & Bajo \\
\hline
\end{tabular}

*Ciclo expresado en $\sum^{\circ} \mathrm{C} /$ día (Temperatura base: $10{ }^{\circ} \mathrm{C}$ ) desde siembra a floración femenina (R1) (Ritchie y Hanway, 1982). Fuente: Alberto Peper (Monsanto S.A., Comunicación Personal), Pedro Capristo (Pioneer, Comunicación Personal).

\section{II.2.2. Manejo del cultivo y diseño experimental.}

Durante el primer año se evaluaron dos ambientes, sembrados el 12/10/2006 y el 4/12/2006 en la localidad de Vicente Casares, Partido de Cañuelas (3459'56,98“'S; 58 40`34,88“O), conformando los A 1 y 2 respectivamente. En 2007, se sembró el 8/11en la misma localidad, lo que constituyó el A 3 (Imagen 1). Por último, se sembró el 15/11/2009 en la localidad de Virrey del Pino, Partido de la Matanza (3449’59,45's; 58 43'17,98“'O), en el Campo Experimental de la Facultad de Ciencias Agrarias de la Universidad Nacional de Lomas de Zamora, correspondiendo el cuarto ambiente bajo estudio (Imagen 2).

Luis Ézequiel García Stepien. 'Iesis de Magister Scientiae en Ciencias Agrarias. Mención en Producción Vegetal. 


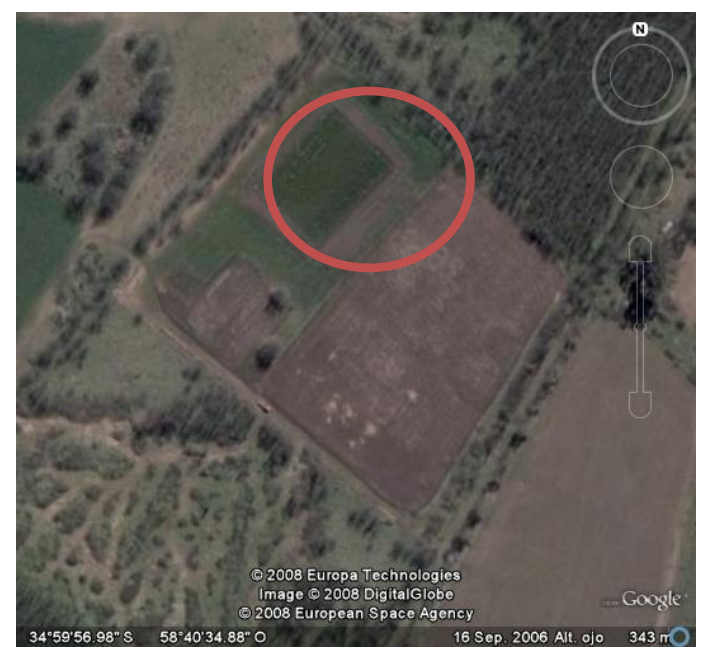

Imagen 1. Imagen satelital del predio ubicado en la localidad Vicente Casares, Partido de Cañuelas

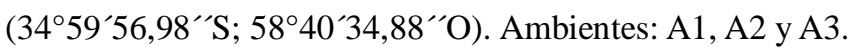

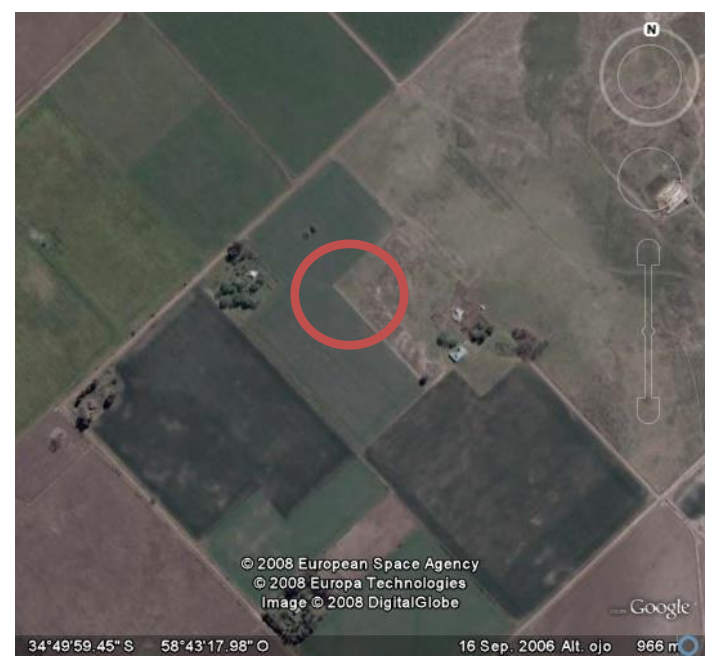

Imagen 2. Imagen satelital del predio ubicado en la localidad de Virrey del Pino, Partido de la Matanza.

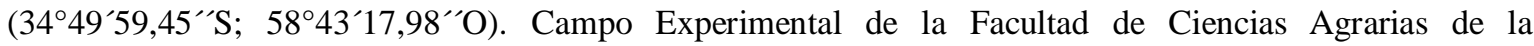
Universidad Nacional de Lomas de Zamora. Ambiente: A4.

La siembra se realizó en forma manual, colocando dos semillas por golpe. Las parcelas experimentales consistieron en dos surcos de $10 \mathrm{~m}$ de largo, separados a $0,5 \mathrm{~m}$ entre sí.

En el estadio de $V_{3}$ de la escala fenológica de Ritchie y Hanway (1982) se realizó el raleo de plantas para obtener la densidad final de 8 plantas $\mathrm{m}^{-2}$ y se fertilizó con $100 \mathrm{~kg}$ ha ${ }^{1}$ de fosfato diamónico. En V6, se fertilizó con $100 \mathrm{~kg} \mathrm{ha}^{-1}$ de urea, con la finalidad de asegurar la suficiencia nutricional del cultivo. 
El control preventivo de insectos de suelo se efectuó mediante la aplicación de carbofurán, formulación líquida, directamente al surco de siembra. Con el objetivo de prevenir la interferencia por malezas, se realizó un control químico mediante la aplicación de $41 \mathrm{ha}^{-1}$ de atrazina, $21 \mathrm{ha}^{-1}$ de acetoclor y $0,51 \mathrm{ha}^{-1}$ de flumetsulam en preemergencia.

\section{II.2.3. Mediciones.}

A los efectos de lograr una caracterización meteorológica de cada uno de los ambientes evaluados se registraron las temperaturas medias del aire y las precipitaciones caídas durante los distintos ciclos de cultivo. Se registró la temperatura media desde siembra a R1 (Ritchie y Hanway, 1982) para poder caracterizar el período vegetativo en cada uno de los ambientes evaluados.

La cosecha se realizó cuando el contenido de materia seca de la planta completa (\%MSpc) se encontraba dentro de la ventana óptima de picado (30-40\%) (Lusk, 1978). Este momento fue definido mediante cortes semanales y secado del material en estufa con circulación forzada de aire a $60^{\circ} \mathrm{C}$ de dos plantas provenientes de surcos adyacentes. En el momento determinado como óptimo para la cosecha, se cortaron diez plantas elegidas al azar en estado de competencia perfecta (cinco plantas de cada uno de los dos surcos).

La fracción vegetativa de dos plantas tomadas al azar se trozó en estratos de $30 \mathrm{~cm}$, partiendo desde una altura de $5 \mathrm{~cm}$ del suelo, conformando estratos compuestos por caña + hojas sobre los cuales se hicieron las determinaciones.

Debido a que la altura de los híbridos es un carácter que puede variar ampliamente entre ambientes, inclusive entre los bloques, se tomó el valor de altura relativa (AR\%) de cada uno de los estratos para poder compararlos. Para ello se determinó el valor de altura de planta como el valor de $100 \%$ de altura relativa y a cada uno de los estratos se le asignó el valor del porcentaje que representa de la altura de planta.

Sobre cada uno de los estratos se calcularon las siguientes variables:

Contenido de materia seca de caña + hojas $(\% M S c+h)$.

Rendimiento en materia seca de caña + hojas $(R M S c+h)$. 
Las muestras fueron molidas mediante un molino de cuchillas con malla de $1 \mathrm{~mm}$ para poder determinar la variable relacionada con la calidad:

Digestibilidad in vitro de la materia seca de caña + hojas $($ Divc $+h)$.

Los análisis de calidad forrajera se llevaron a cabo mediante el uso de espectrometría cercana al infrarrojo (NIRS - Near infrared reflectance spectroscopy - Foss 6500). Las curvas de calibración empleadas para determinar la digestibilidad in vitro, se generaron basándose en el método enzimático (Pepsina + celulasa), utilizando bolsas filtrables (Vogel et al., 1999) en incubador Daisy II (Ankom).

\section{II.2.4. Análisis estadístico:}

Se emplearon modelos de regresión bisegmentados con el objetivo de evaluar la distribución vertical de las distintas variables en la fracción vegetativa de la planta de maíz, comparando diversos genotipos y ambientes. Debido a la naturaleza no lineal de los datos, se buscó utilizar una metodología que simplifique la interpretación de los datos y posibilite la comparación entre los genotipos y ambientes evaluados. Esta metodología de análisis fue empleada por Miralles et al. (1996) para evaluar el crecimiento de grano en líneas de trigo, siendo el modelo acorde para la simplificación y posterior análisis modelos complejos de regresión no lineales. La elección de altura de inserción de la espiga, como punto de inflexión del modelo, se desprendió del análisis exploratorio de los datos donde se destacó como punto de quiebre en el comportamiento de los mismos.

$$
\begin{aligned}
& Y_{1}=\alpha_{1}+\beta_{1} \times X \\
& Y_{\text {enX0 }}=\beta_{1} \times X_{0}+\alpha_{1} \\
& Y_{2}=Y_{\text {enX0 }}+\beta_{2} \times\left(X-X_{0}\right) \\
& Y=S_{I}\left(X<X_{0}, Y_{1}, Y_{2}\right)
\end{aligned}
$$


$\mathrm{Y}_{1}$ : Media general del ensayo para la variable considerada por debajo de la altura de inserción de la espiga.

$\mathrm{Y}_{2}$ : Media general del ensayo para la variable considerada por arriba de la altura de inserción de la espiga.

$\alpha_{1}$ : Coordenada al origen.

$\beta_{1}$ : Tasa de variación por debajo de $\mathrm{X}_{0}(\Delta \mathrm{MSb}, \Delta \mathrm{RMSb}$ y $\Delta \mathrm{Divb})$.

$\beta_{2}$ : Tasa de variación por arriba de $\mathrm{X}_{0}(\Delta \mathrm{MSs}, \Delta \mathrm{RMSs}$ y $\Delta \mathrm{D} i v \mathrm{~s})$.

$\mathrm{Y}_{\mathrm{enX} 0}$ : Media general del ensayo para la variable considerada de la fracción vegetativa a $\mathrm{X}_{0}$.

$\mathrm{X}$ : Altura relativa de la fracción vegetativa (AR\%).

$\mathrm{X}_{0}$ : Altura de inserción de la espiga (AR\%).

Se analizaron mediante un ANVA los valores $\beta_{1}$ y $\beta_{2}$, obtenidos para cada variable, con el propósito de evaluar los efectos de los tratamientos y sus interacciones. Se utilizó el procedimiento GLM del programa estadístico SAS. Las comparaciones entre medias se realizaron mediante la utilización del test de Diferencias Mínimas Significativas (DMS) con un nivel de significancia de $\mathrm{p}<0,05$. Para el análisis se empleó un diseño de bloques completos aleatorizados con tres repeticiones. Las fuentes de variación correspondieron a ambientes, bloques anidados en ambientes, híbridos y las respectivas interacciones. Los ambientes fueron considerados como efectos aleatorios, mientras que los híbridos fueron considerados como efectos fijos, con lo cual se generó un modelo mixto, resuelto de acuerdo a McInstosh, (1983):

$\mathrm{Y}_{\alpha \gamma \delta}=\mu+\alpha+\beta(\alpha)+\gamma+\alpha \times \gamma+\varepsilon_{\alpha \gamma}$

Donde:

$\boldsymbol{\mu}=$ Media general del ensayo para la variable considerada.

$\boldsymbol{\alpha}=$ Efecto del ambiente.

$\boldsymbol{\beta}(\boldsymbol{\alpha})=$ Efecto de bloque anidado en ambientes .

$\gamma=$ Efecto del híbrido.

$\boldsymbol{\alpha} \times \boldsymbol{\gamma}=$ Interacción ambiente $\times$ híbrido.

$\boldsymbol{\varepsilon}_{\boldsymbol{\alpha} \gamma}=$ Error experimental. 


\section{II.3. RESULTADOS Y DISCUSIÓN.}

Las condiciones meteorológicas difirieron entre los ambientes evaluados. La temperatura media del aire durante el período siembra-floración fue más elevada en A2 $\left(23,6{ }^{\circ} \mathrm{C}\right)$ y menor en A1 y A3 $\left(20,3\right.$ y $20,9{ }^{\circ} \mathrm{C}$ respectivamente), mientras que A4 presentó características intermedias $\left(21,9{ }^{\circ} \mathrm{C}\right)$ (Tabla 2). El cultivo no sufrió períodos prolongados de exposición a temperaturas mayores a $\operatorname{los} 34{ }^{\circ} \mathrm{C}$, lo cual permitió el crecimiento y desarrollo normales del mismo. Este valor máximo de temperatura fue establecido por diversos autores (Tollenaar et al., 1979; Andrade et al., 1996).

Tabla 2. Temperatura media del aire del periodo siembra - R1 (Ritchie y Hanway, 1982).

\begin{tabular}{cccc}
\hline Ambiente & Siembra & Floración (R1) & Temperatura media del aire ${ }^{\circ} \mathbf{C}$ \\
\hline 1 & $12 / 10 / 2006$ & $21 / 12 / 2006$ & 20,3 \\
2 & $4 / 12 / 2006$ & $27 / 01 / 2007$ & 23,6 \\
3 & $8 / 11 / 2007$ & $12 / 01 / 2008$ & 20,9 \\
4 & $15 / 11 / 2009$ & $15 / 01 / 2010$ & 21,9 \\
\hline
\end{tabular}

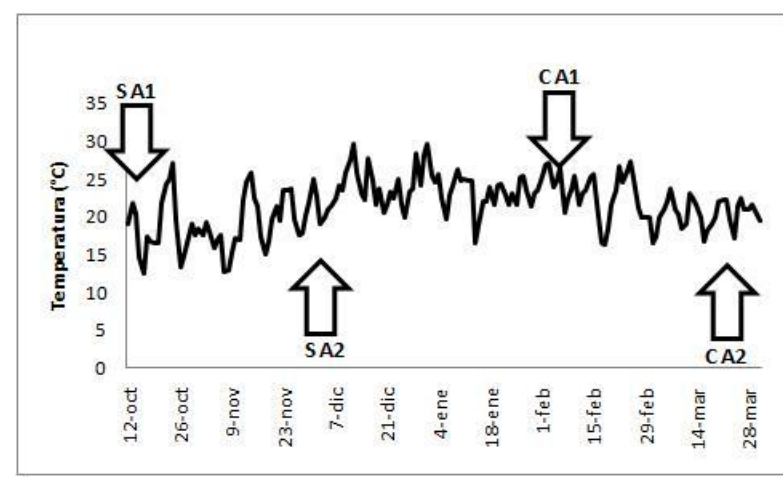

1.a

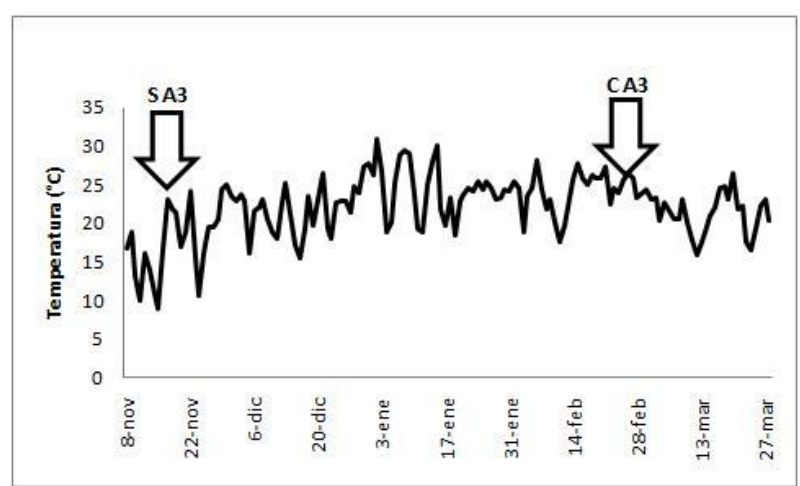

Luis Ezequiel García Stepien. Tesis de Magister Scientiae en Ciencias Agrarias. Mención en Producción Vegetal. Facultad de Ciencias Agrarias y Forestales. UNLP. 
$1 . b$

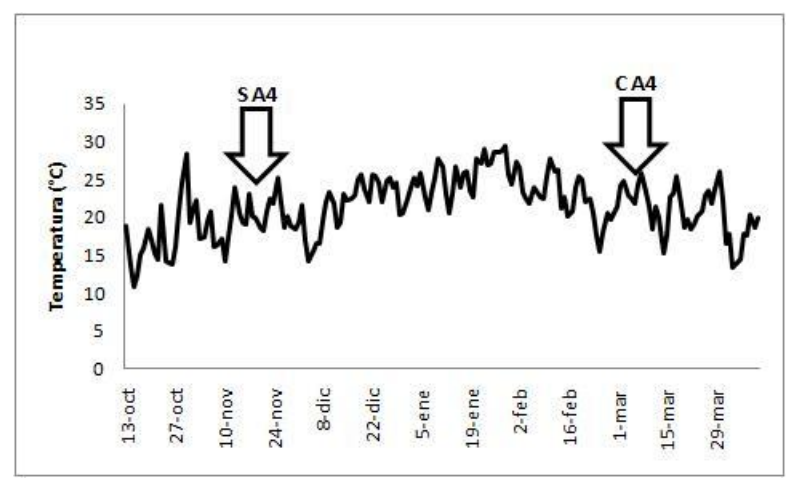

1.c

Figura 1. Temperatura media del aire medida en ${ }^{\circ} \mathrm{C}(\mathrm{a}, \mathrm{b}, \mathrm{c})$

1.a. Vicente Casares, Partido de Cañuelas, Provincia de Buenos Aires. A1 y A2. SA1 (Siembra Ambiente 1, 12/10/ 2006); SA2 (Siembra Ambiente 2, 4/12/2006); CA1 (Cosecha Ambiente 1, 6/2/2007); CA2 (Cosecha Ambiente 2, 26/3/2007). 1.b. Vicente Casares, Partido de Cañuelas, Provincia de Buenos Aires. A3. SA3 (Siembra Ambiente 3, 8/11/2007); CA3 (Cosecha Ambiente 3, 27/2/2008). 1.c. Virrey del Pino, Partido de La Matanza, Provincia de Buenos Aires. A4. SA4 (Siembra Ambiente 4, 15/11/2009); CA4 (Cosecha Ambiente 4, 4/3/2010).

El patrón de distribución de precipitaciones en el período que se extiende desde septiembre hasta abril fue adecuado para el cultivo en A1, A2 y A4 (Figura 2), donde la distribución de lluvias fue similar a la esperable, de acuerdo a los valores medios zonales. Aún cuando en el mes de enero, en A1 y A2, se registró un nivel de precipitaciones inferior, no coincidió con en el período crítico de requerimiento hídrico ( $\mathrm{R} 1 \pm 15$ días) (Ritchie y Hanway, 1982), restableciéndose en el mes de febrero el estado hídrico del suelo.

Por su parte, A3 puede definirse como un ambiente menos favorable para el cultivo, dado que se observó menor valor de precipitaciones, especialmente durante diciembre y enero (Figura 2). Durante el mes de enero los seis híbridos alcanzaron el período crítico de requerimiento hídrico. 


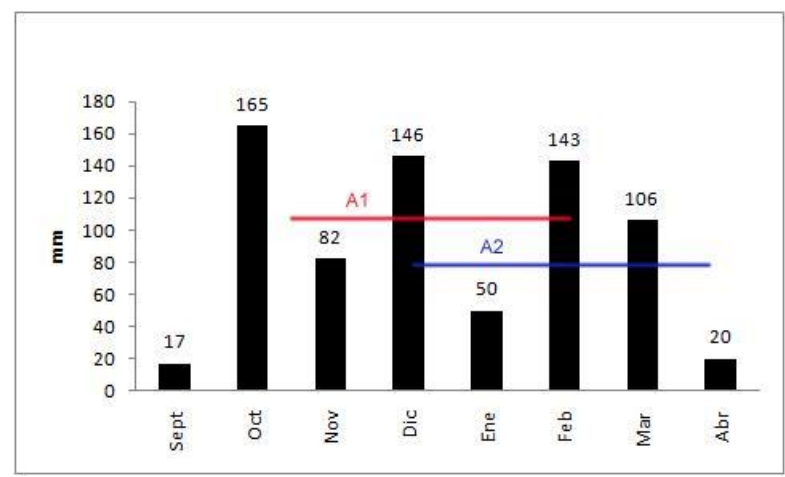

2.a

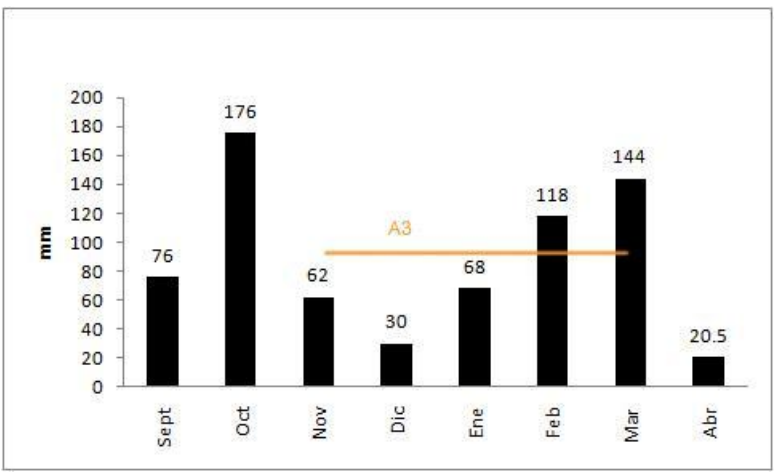

2.b

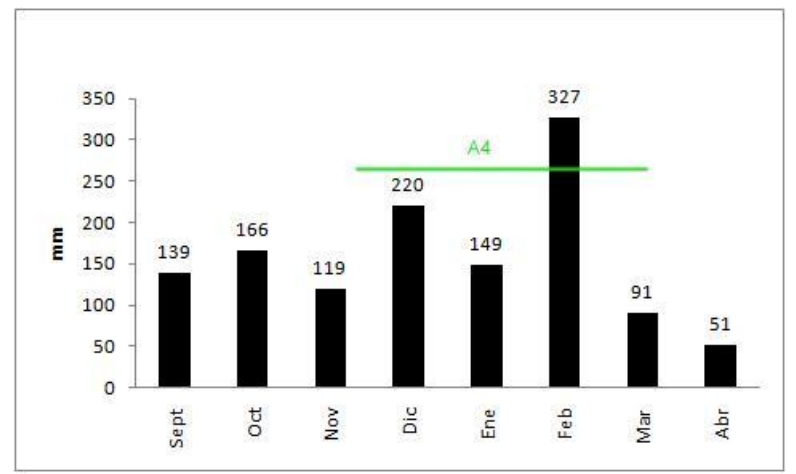

2.c

Figura 2. Precipitaciones mensuales ( $\mathrm{mm} / \mathrm{mes})$.

2.a. Vicente Casares, Partido de Cañuelas, Provincia de Buenos Aires.A1 y A2. (A1: Siembra A1, 12/10/ 2006; Cosecha A1, 6/2/2007); (A2: Siembra A2, 4/12/2006; Cosecha A2, 26/3/2007). 2.b. Vicente Casares, Partido de Cañuelas, Provincia de Buenos Aires. A3. (A3: Siembra A3, 8/11/2007; Cosecha A3, 27/2/2008). 2.c. Virrey del Pino, Partido de La Matanza, Provincia de Buenos Aires. A4. (A4: Siembra A4, 15/11/2009; Cosecha A4, 4/3/2010).

Luis Ezequiel García Stepien. Tesis de Magister Scientiae en Ciencias Agrarias. Mención en Producción Vegetal. Facultad de Ciencias Agrarias y Forestales. UNLP. 


\section{Genotipos.}

Los híbridos utilizados para el experimento mostraron un rango de ciclo similar, que en promedio osciló entre 112 y 115 días desde siembra a cosecha (Tabla 3). Estos valores son concordantes con los descriptos por los obtentores.

Tabla 3. Caracterización morfológica y fenológica de los seis híbridos de maíz.

\begin{tabular}{clccc}
\hline Híbrido & \multicolumn{2}{c}{ Siembra - Cosecha } & Altura de planta* & $\begin{array}{c}\text { Inserción de } \\
\text { espiga* } \\
\end{array}$ \\
& días & $\sum^{\circ}$ C/día** & cm & cm \\
\hline 31B18 & 115 & 1433 & 209,42 & 108,00 \\
30R76 & 112 & 1383 & 207,92 & 105,75 \\
31A25 & 113 & 1383 & 215,08 & 116,92 \\
AW 190 MG & 113 & 1383 & 218,42 & 103,75 \\
DK 747 MG & 113 & 1383 & 198,25 & 102,67 \\
DK 670 MG & 114 & 1405 & 192,75 & 99,50 \\
\hline
\end{tabular}

Valores promedio de los cuatro ambientes utilizados.* Características medidas a Cosecha. **SiembraCosecha (temperatura base $=10^{\circ} \mathrm{C}$ ).

\section{Distribución del rendimiento en materia seca de la fracción vegetativa.}

La distribución del rendimiento en materia seca de la fracción vegetativa (RMS) se ajustó a un modelo de regresión bisegmentado con su punto de inflexión ubicado a la altura de la espiga (Figura 3). El máximo RMS se ubicó en la base de la planta y decrece hacia la panoja, coincidiendo con lo descripto por Alessandro (2002), quien asocia este comportamiento a las variaciones que sufre diámetro del tallo desde la base de la planta hacia el ápice de la misma. Por el contrario, en el A2 se caracterizó por un aporte menor de los estratos basales y un incremento en el aporte al rendimiento a medida que se acerca a X0, para luego disminuir hacia la panoja (Figura 3). Esto se asoció al aporte de las hojas descripto por Sadras et al. (2000), donde el máximo se encuentra a la altura de la espiga para disminuir hacia los extremos. También a una alta relación hoja/tallo debido a la mayor elongación de los entrenudos y al menor diámetro del tallo de acuerdo a los resultados obtenidos por varios autores (Tollenaar et al., 1979; Andrade et al.,1996; Adugna y Sundstol, 1999), lo cual potenció el efecto anterior. 
Ambiente 1

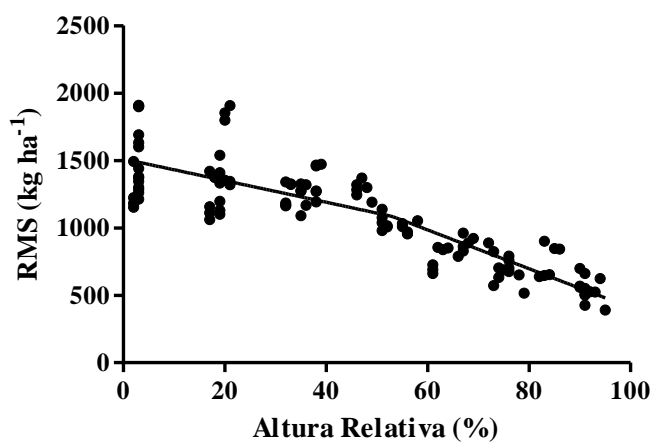

Ambiente 2

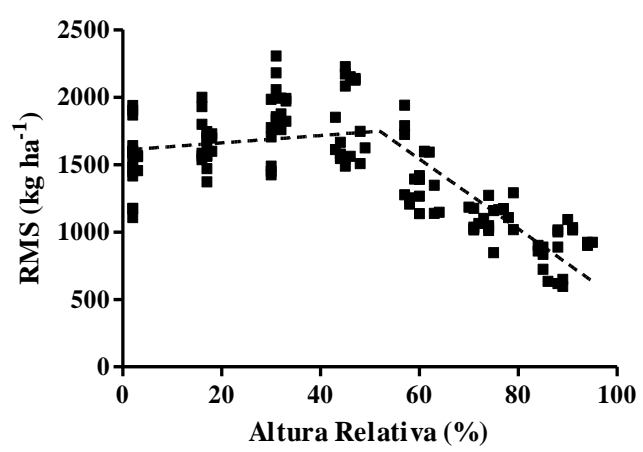

Ambiente 3

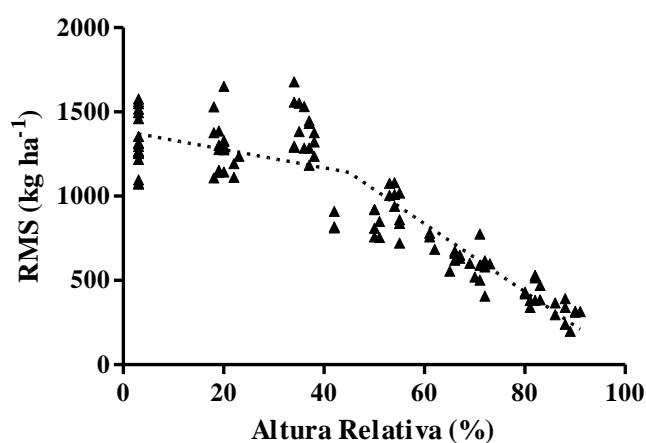

Ambiente 4

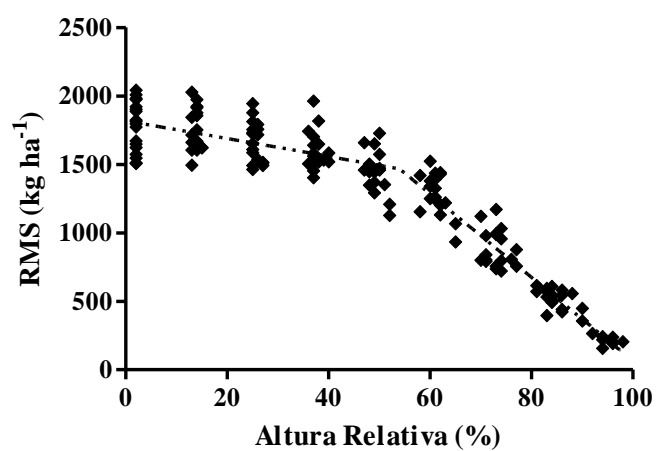

Figura 3. Distribución vertical del Rendimiento Materia Seca vegetativa (RMS,kg ha ${ }^{-1}$ ) en la fracción vegetativa de la planta de maíz. Promedio de 6 híbridos comerciales en 4 A.

\section{Tasa de variación del rendimiento en materia seca por debajo de la espiga ( $\Delta R M S b)$.}

Tabla 4. Análisis de varianza para $\triangle \mathrm{RMSb}\left(\mathrm{kg} \% \mathrm{AR}^{-1}\right)$ empleando un modelo mixto de 6 híbridos comerciales (efecto fijo), en 4 A (efecto aleatorio).

\begin{tabular}{lccccc}
\hline FV & GL & SC & CM & F & P(\%) \\
\hline A & 3 & 1206,32 & 402,11 & 5,55 & 0,91 \\
G & 5 & 258,79 & 51,76 & 0,71 & 62,22 \\
Bloques(A) & 8 & 7,980620 & 1,00 & 1,03 & 42,75 \\
A $\times$ G & 15 & 1086,70 & 72,45 & 75,07 & $<0,01$ \\
Error & 40 & 38,60 & 0,96 & & \\
\hline
\end{tabular}

Al analizar la tasa de variación del rendimiento en materia seca por debajo de la altura de inserción de la espiga ( $\triangle \mathrm{RMSb})$, se observó una interacción $\mathrm{G} \times \mathrm{A}$ altamente significativa, por lo que se optó por describir los ambientes por separado. El ambiente generó diferencias significativas $(\mathrm{p}=0,91)$, pudiéndose distinguir dos líneas de comportamiento: en la primera se agrupan A1, A3 y A4, mientras que la segunda se encontró representada por A2 con un comportamiento opuesto (Figura 3). Dentro del Luis Ezequiel García Stepien. Tesis de Magister Scientiae en Ciencias Agrarias. Mención en Producción Vegetal. 
primer grupo se observó que el mayor aporte al $\mathrm{RMSc}+\mathrm{h}$ lo realizan los estratos basales de la planta. Luego este aporte decrece a medida que ascendemos hacia la altura de inserción de la espiga $\left(\mathrm{X}_{0}\right)$, debido principalmente a la disminución del diámetro del tallo. Este comportamiento se condice con los resultados obtenidos por King et al. (1971) al evaluar híbridos templados y tropicales. Por el contrario, el A2 se caracterizó por un aporte menor de los estratos basales y un incremento en el aporte al rendimiento a medida que nos acercamos a $\mathrm{X}_{0}$. Este ambiente presentó un valor promedio de ganancia de 2,5 kg de MS/unidad de AR\%, mientras que en el resto se aprecian un rango de pérdida comprendido entre 5,2 y 8,2 kg de MS/unidad de AR\%, para el A3 y el A1 respectivamente (Tabla 5). El comportamiento de los genotipos no difirió significativamente dentro de los ambientes (Tabla 4), por lo que se asumió que todos los híbridos analizados distribuyen el RMS de manera similar por debajo de la espiga, dependiendo de las condiciones ambientales imperantes.

Tabla 5. Medias de $\Delta \mathrm{RMSb}\left(\mathrm{kg} \% \mathrm{AR}^{-1}\right)$, para los 4 Ambientes evaluados.

\begin{tabular}{cc}
\hline Ambiente & $\Delta$ RMSb $\left(\mathbf{k g ~ \% a l t u r a ~}^{-1}\right)$ \\
\hline 2 & $2,50 \mathrm{a}$ \\
3 & $-5,17 \mathrm{~b}$ \\
4 & $-6,48 \mathrm{c}$ \\
1 & $-8,22 \mathrm{~d}$ \\
\hline
\end{tabular}

Dentro de cada columna valores seguidos de la misma letra no difieren significativamente a un nivel de probabilidad $\mathrm{P}<0.05$. 
Tasa de variación del rendimiento en materia seca por arriba de la espiga ( $\Delta R M S s)$.

Tabla 6. Análisis de varianza para $\triangle \mathrm{RMSs}\left(\mathrm{kg} \% \mathrm{AR}^{-1}\right)$ empleando un modelo mixto de 6 híbridos comerciales (efecto fijo), en 4 Ambientes (efecto aleatorio).

\begin{tabular}{lccccc}
\hline FV & GL & SC & CM & F & P(\%) \\
\hline A & 3 & 2969,63 & 989,88 & 11,20 & 0,05 \\
G & 5 & 110,63 & 22,13 & 0,24 & 93,72 \\
Bloques (A) & 8 & 31,99 & 4,00 & 0,59 & 78,29 \\
A $\times$ G & 15 & 1368,22 & 91,21 & 13,38 & $<0,01$ \\
Error & 40 & 272,73 & 6,82 & & \\
\hline
\end{tabular}

La $\triangle$ RMSs presentó una interacción G×A significativa (Tabla 6). El ambiente generó diferencias significativas ( $\mathrm{p}=0,05 \%)$, en todos los casos se apreció una disminución en el aporte al RMS de la fracción vegetativa a medida que se incrementa la altura de evaluación hacia la panoja (Figura 3). Esta disminución en el rendimiento, pudo deberse al decrecimiento que sufren el diámetro del tallo y el tamaño de las hojas cercanas a la panoja descripto por King et al. (1971). La $\triangle$ RMSs mínima se observa el A1, con un valor promedio de pérdida de $13,46 \mathrm{~kg}$ de MS/unidad \%AR y máxima en el A4, con un valor promedio de pérdida de 30,86 kg de MS/unidad de \%AR (Tabla 7). El comportamiento de los genotipos no difirió significativamente dentro de los ambientes, por lo que podría inferirse que los híbridos estudiados distribuyen el RMS de manera similar por arriba de la espiga. Estos resultados coinciden con los obtenidos por King et al. (1971). Los mismos muestran que el aporte generado por los estratos de la fracción vegetativa que se encuentran por arriba de la espiga, disminuyen hacia la panoja. Asimismo, coinciden con los de Alessandro (2002), en que esta sección es la de menor aporte en MS al rendimiento de la fracción vegetativa de la planta. 
Tabla 7. Medias de $\Delta$ RMSs $\left(\mathrm{kg} \% \mathrm{AR}^{-1}\right)$, para los 4 Ambientes evaluados.

\begin{tabular}{cc}
\hline Ambiente & $\Delta$ RMSs $\left(\mathbf{k g} \%\right.$ altura $\left.^{-1}\right)$ \\
\hline 1 & $-13,46 \mathrm{a}$ \\
3 & $-20,27 \mathrm{~b}$ \\
2 & $-25,41 \mathrm{c}$ \\
4 & $-30,86 \mathrm{~d}$ \\
\hline
\end{tabular}

Dentro de cada columna valores seguidos de la misma letra no difieren significativamente a un nivel de probabilidad $\mathrm{P}<0,05$.

Todos los híbridos presentan igual comportamiento ante la distribución vertical del rendimiento (Tabla 5), a pesar de poseer origen genético distinto y estar considerados con distinto grado de Stay green.

\section{Distribución vertical del contenido de materia seca de la fracción vegetativa.}

Esta variable (\%MS) puede ajustarse a un modelo de regresión bisegmentado con su punto de inflexión ubicado a la altura de la espiga (Figura 4). El máximo \%MS de la planta se ubica en el ápice y desciende hacia la altura de inserción de la espiga, para luego hacerse relativamente constante hacia la base. Si bien este comportamiento coincidió en líneas generales con el perfil de senescencia foliar descrito por Borrás et al. (2003) y Valentinuz et al. (2004), sus variaciones en el momento óptimo para ensilar (30-40\%MSpc) dependieron en mayor medida del efecto ambiental más que de las diferencias en el grado de Stay green de los híbridos utilizados. Esto último pudo deberse a que las variaciones en la senescencia foliar de los híbridos no se tradujeron en variaciones significativas del contenido de MS de la fracción vegetativa (Caña + hojas) en este estadío fenológico del cultivo (R5) (Ritchie y Hanway, 1982). En aquellas fracciones donde está más marcada la senescencia foliar, ápice y base de la planta, la relación hoja/tallo es baja, por lo tanto estas diferencias no afectaron a los parámetros productivos.

Se observó en todos los genotipos, coincidiendo con Rimieri et al. (2001) y Alessandro (2002), un \% MS menor en la sección inferior a la espiga. Según Borrás et al., 2003, esto se debería a que la senectud es un proceso altamente conservativo que no se limita únicamente a un nivel celular o de las hojas basales, sino de toda la planta, donde su iniciación esta genéticamente controlada. Finalizada la senescencia de la panoja, la misma 
deja de ejercer su dominancia apical y la planta posee como destino principal a la espiga, incrementándose en este momento la magnitud del secado de la parte superior, siendo el destino el que regula la actividad del tercio del canopeo que abastece a la espiga.

Ambiente 1

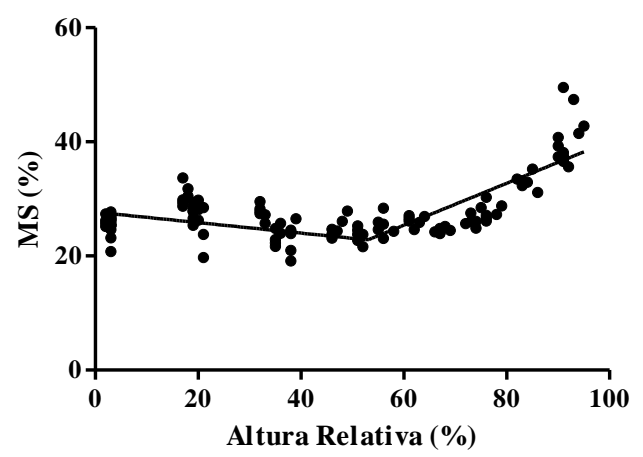

Ambiente 2

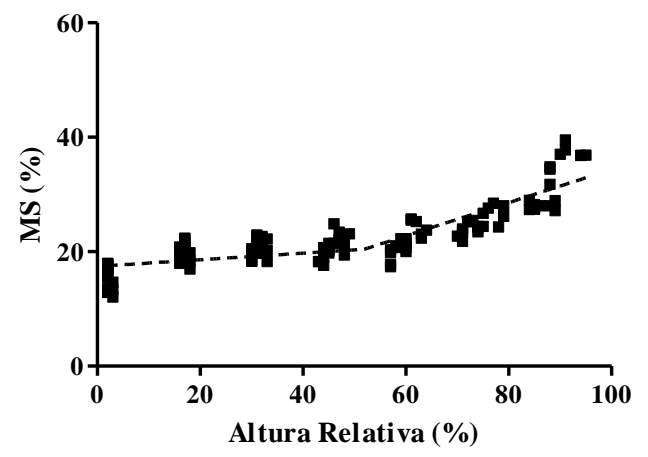

Ambiente 3

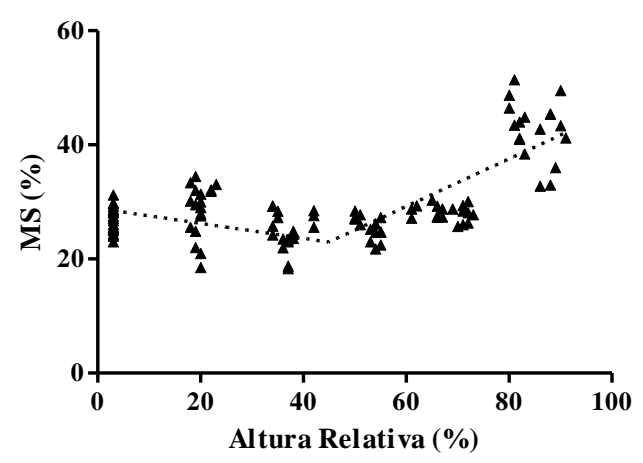

Ambiente 4

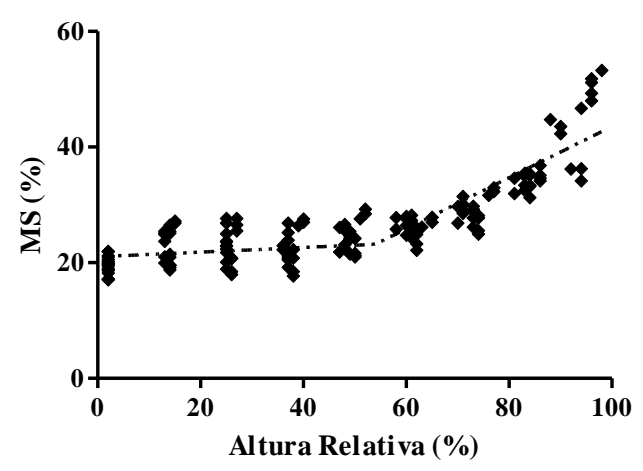

Figura 4. Distribución vertical del contenido de materia seca (\%) en la fracción vegetativa de la planta de maíz. Promedio de 6 híbridos comerciales en 4 Ambientes. 
Tasa de variación del contenido de materia seca por debajo de la espiga ( $\Delta \% \mathrm{MSb})$.

Tabla 8. Análisis de varianza para $\Delta \% \mathrm{MSb}\left(\% \mathrm{MS} \% \mathrm{AR}^{-1}\right)$ empleando un modelo mixto de 6 híbridos comerciales (efecto fijo), en 4 A (efecto aleatorio).

\begin{tabular}{lccccc}
\hline FV & GL & SC & CM & F & P(\%) \\
\hline A & 3 & 0,577696 & 0,192565 & 80,48 & $<0,01$ \\
G & 5 & 0,015085 & 0,003017 & 1,17 & 36,83 \\
Bloques (A) & 8 & 0,003729 & 0,000466 & 0,72 & 67,50 \\
A×G & 15 & 0,038646 & 0,002576 & 3,96 & 0,02 \\
Error & 40 & 0,025993 & 0,000650 & & \\
\hline
\end{tabular}

Tabla 9. Medias de $\Delta \% \mathrm{MSb}\left(\% \mathrm{MS} \% \mathrm{AR}^{-1}\right)$, para los 4 ambientes evaluados.

\begin{tabular}{cc}
\hline Ambiente & $\Delta$ MSb $\left(\mathbf{k g ~ \% a l t u r a ~}^{-1}\right)$ \\
\hline 2 & $0,067689 \mathrm{a}$ \\
4 & $0,051593 \mathrm{a}$ \\
1 & $-0,087079 \mathrm{~b}$ \\
3 & $-0,142513 \mathrm{c}$ \\
\hline
\end{tabular}

Dentro de cada columna valores seguidos de la misma letra no difieren significativamente a un nivel de probabilidad $\mathrm{P}<0,05$.

La $\Delta \% \mathrm{MSb}$ presentó una interacción G×A significativa (Tabla 8). El ambiente generó diferencias significativas $(\mathrm{p}=0,01)$, resultando en el A2 la máxima ganancia de \%MS con un valor promedio de $0,068 \% \mathrm{MS} \% \mathrm{AR}^{-1}$ y la máxima la pérdida de $\% \mathrm{MS}$ en el $\mathrm{A} 3$ con un valor promedio de pérdida de $0,14 \% \mathrm{MS} \% \mathrm{AR}^{-1}$ (Tabla 9). Aunque estos valores difieran significativamente, la magnitud de los mismos indican que no se encontraron variaciones en el contenido de MS hasta la altura de inserción de la espiga (Figura 4). El comportamiento de los genotipos no difirió significativamente dentro de los ambientes, por lo que todos los genotipos evaluados distribuyeron la MS de igual manera por debajo de la espiga. Coincidiendo con Alessandro (2002), se observó que ésta sección es la de mayor peso en cuanto a su contribución al rendimiento en MS de la fracción vegetativa total de la planta de maíz. 
Tasa de variación del contenido de materia seca por arriba de la espiga ( $\Delta \% \mathrm{MSs})$.

Tabla 10. Análisis de varianza para $\Delta \% \mathrm{MSs}\left(\mathrm{kg}_{\%}\right.$ altura $\left.^{-1}\right)$ empleando un modelo mixto de 6 híbridos comerciales (efecto fijo), en 4 Ambientes (efecto aleatorio).

\begin{tabular}{lccccc}
\hline FV & GL & SC & CM & F & P(\%) \\
\hline A & 3 & 0,239629 & 0,079876 & 2,62 & 8,79 \\
G & 5 & 0,087515 & 0,017503 & 0,59 & 70,82 \\
Bloques (A) & 8 & 0,028125 & 0,003516 & 1,28 & 28,06 \\
A $\times$ G & 15 & 0,445295 & 0,029686 & 10,82 & $<0,01$ \\
Error & 40 & 0,109769 & 0,002744 & & \\
\hline
\end{tabular}

La $\Delta \%$ MSs presentó una interacción $\mathrm{G} \times \mathrm{A}$ significativa (Tabla 10 ). No se apreciaron diferencias significativas entre ambientes ni entre genotipos, pudiéndose observar para todos los casos un incremento en el \%MS de la fracción vegetativa de la planta de maíz a medida que se incrementa la altura hacia la panoja (Figura 4). Pese a que esta sección es la que menos gravita en cuanto a su contribución al rendimiento en MS de la fracción vegetativa total, su mayor \%MS se incrementa en tanto se aumenta la altura de picado.

\section{Distribución Vertical de la Calidad de la Fracción Vegetativa.}

La distribución de la Div en el perfil vertical de la planta de maíz se ajustó a un modelo de regresión bisegmentado con su punto de inflexión ubicado a la altura de la espiga, punto de máxima calidad. Este comportamiento fue similar al encontrado por Wu y Roth (2003) y Alessandro et al. (2005) (Figura 5), quienes apreciaron que la menor calidad nutricional de la fracción vegetativa se ubica en la sección inferior de la planta. 

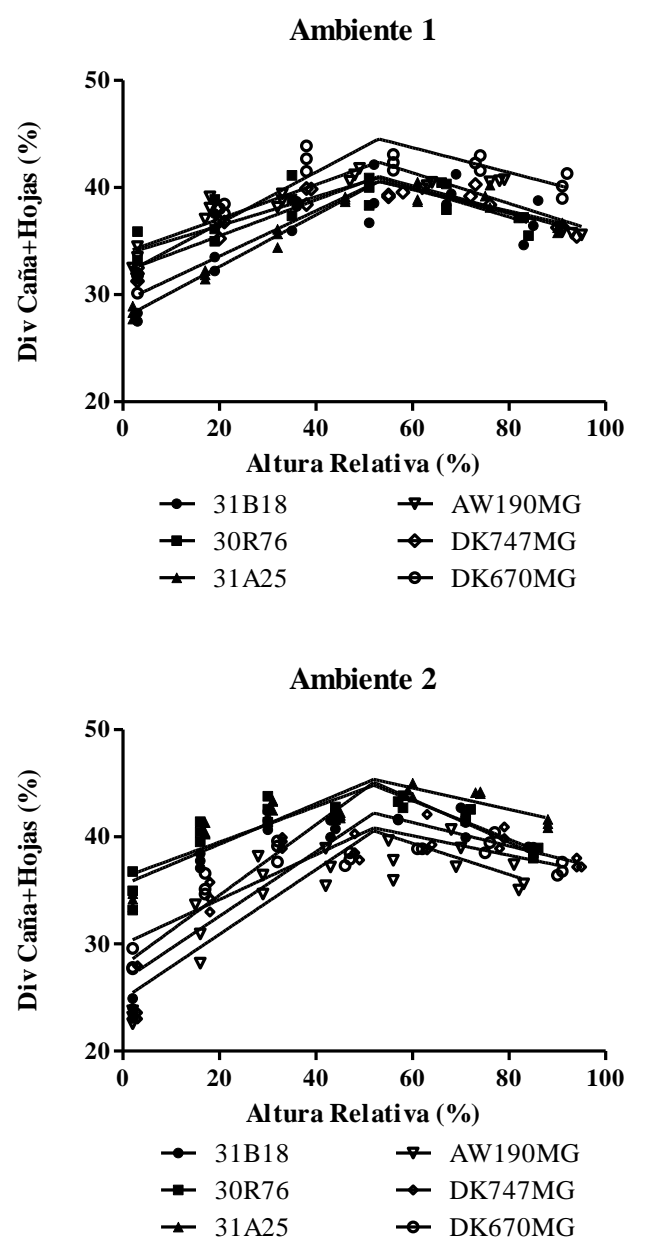
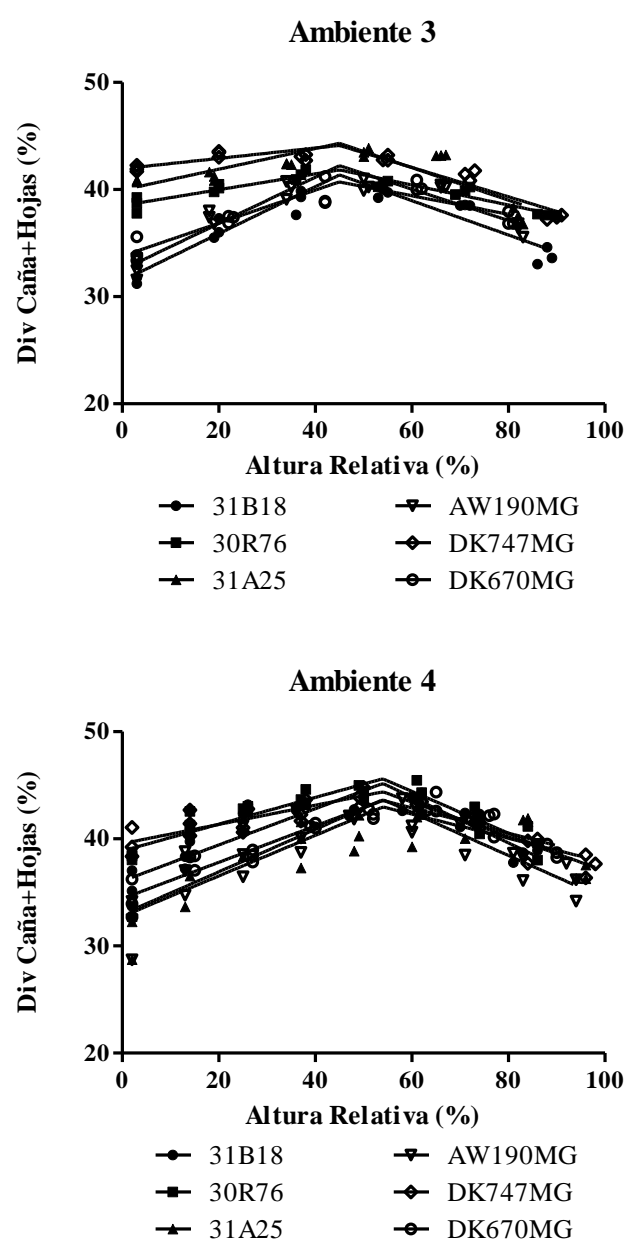

Figura 5. Distribución vertical de la Digestibilidad in vitro (\%) de la fracción vegetativa de la planta de maíz, de 6 híbridos comerciales en 4 ambientes.

Tasa de Variación de la Digestibilidad in vitro por debajo de la espiga ( $\Delta$ Divb).

Tabla 11. Análisis de varianza para $\Delta \mathrm{D} i v \mathrm{~b}\left(\% \mathrm{D} i v \% \mathrm{AR}^{-1}\right)$ empleando un modelo mixto de 6 híbridos comerciales (efecto fijo), en 4 Ambientes (efecto aleatorio).

\begin{tabular}{lccccc}
\hline FV & GL & SC & CM & F & P(\%) \\
\hline A & 3 & 0,140969 & 0,046990 & 6,85 & 0,48 \\
G & 5 & 0,134348 & 0,026870 & 3,74 & 2,13 \\
Bloques (A) & 8 & 0,001675 & 0,000209 & 0,39 & 91,95 \\
A G & 15 & 0,107819 & 0,007188 & 13,40 & 0,01 \\
Error & 40 & 0,021460 & 0,000537 & & \\
\hline
\end{tabular}

Luis Ezequiel García Stepien. Tesis de Magister Scientiae en Ciencias Agrarias. Mención en Producción Vegetal. Facultad de Ciencias Agrarias y Forestales. UNLP. 
Tabla 12. Medias de $\Delta \mathrm{Divb}\left(\% \mathrm{Div} \% \mathrm{AR}^{-1}\right)$, para los 4 Ambientes evaluados.

\begin{tabular}{cc}
\hline Ambiente & $\Delta$ Divb (\%Div \%altura-1) \\
\hline 2 & $0,251883 \mathrm{a}$ \\
1 & $0,191494 \mathrm{~b}$ \\
4 & $0,153822 \mathrm{c}$ \\
3 & $0,136483 \mathrm{~d}$ \\
\hline
\end{tabular}

Dentro de cada columna valores seguidos de la misma letra no difieren significativamente a un nivel de probabilidad $\mathrm{P}<0,05$.

La Tasa de Variación de la Digestibilidad in vitro por debajo de $\mathrm{X}_{0}(\Delta \mathrm{D} i v \mathrm{~b})$ presentó una interacción $\mathrm{G} \times \mathrm{A}$ significativa $(\mathrm{p}<0,0001)$ (Tabla 11). El ambiente generó diferencias significativas ( $\mathrm{p}=0,0048$ ), siendo la $\Delta \mathrm{D} i v \mathrm{~b}$ mínima en el $\mathrm{A} 3$, representada por una ganancia promedio de $0,14 \%$ Div $\% \mathrm{AR}^{-1}$ y máxima en el A2 con un valor promedio de 0,25\% Div $\% \mathrm{AR}^{-1}$ (Tabla 12). Esto último podría deberse a que el $\mathrm{A} 2$ corresponde a una fecha de siembra tardía. En este ambiente, se registró una mayor temperatura durante el periodo siembra-R1, lo cual produjo una caída de mayor magnitud en la calidad nutricional de la fracción vegetativa. Esto coincidió con lo descripto por Buxton (1996), quien estableció una relación inversa entre la temperatura y la calidad forrajera. Asimismo, un incremento en la translocación de asimilados desde la caña hacia la espiga en este ambiente podría provocar la caída observada en la calidad nutricional de la porción vegetativa. Esto último coincide parcialmente con la mayor translocación de fotoasimilados descripta por Kiniry, et al. (1992) ante condiciones limitantes de radiación en postfloración. Ambos efectos pudieron causar esta distribución más acentuada de la calidad nutricional en la fracción vegetativa. El comportamiento de los genotipos difiere significativamente $(p=0,0213)$ (Tabla 11), pudiéndose observar dos grupos diferenciados. El primero (Híbridos: AW190MG, 31B18 y DK670MG), representa a híbridos cuya ganancia de calidad al acercarse a la altura de inserción de la espiga es muy marcada. Estos genotipos se caracterizan por tener una distribución poco homogénea de la calidad, mientras que en el segundo grupo, (Híbridos: 31A25, DK747MG y 30R76), se encuentran aquellos genotipos donde la variación de la digestibilidad entre la base de la planta y la altura de inserción de la espiga difiere en menor grado, esto es representado por una menor $\Delta \mathrm{D} i v \mathrm{~b}$ con valores cercanos a $0,15 \%$ Div $\% \mathrm{AR}^{-1}$ (Tabla 13). Para no comprometer la calidad nutricional durante el proceso de ensilado, se debería considerar la utilización de alturas de corte mayores a $60 \mathrm{~cm}$ en aquellos genotipos cuyas tasas de variación de la digestibilidad sean superiores a $0,20 \% \mathrm{D} i v \% \mathrm{AR}^{-1}$ (Tabla 13$)$.

Luis Ezequiel García Stepien. Tesis de Magister Scientiae en Ciencias Agrarias. Mención en Producción Vegetal. 
Estas variaciones en la distribución no se asociaron con el grado de carácter Stay green de los híbridos, posiblemente debido a que al momento de realizar el picado (R5, Ritchie y Hanway, 1982), este carácter no logró el nivel de expresión necesario como para generar diferencias con respecto a los genotipos normales. Tales resultados podrían deberse a que el proceso de senescencia foliar presenta una baja tasa entre floración (R1) y la mitad del llenado de granos, mientras que después de este período la tasa de senescencia se cuadriplica (Borrás et al., 2003 y Valentinuz et al., 2004).

La variación entre los genotipos (Tablas 10 y 12) justificó el estudio de los patrones de distribución de la Div y el mismo debería ser un carácter a tener en cuenta en los programas de mejoramiento.

Tabla 13. Medias de $\Delta$ Divb (kg \%altura $\left.{ }^{-1}\right)$, para los 6 Híbridos evaluados.

\begin{tabular}{cc}
\hline Híbridos & $\Delta$ Div $\left(\% \mathbf{D} \boldsymbol{i}\right.$ \% $\left.\mathbf{A R}^{\mathbf{- 1}}\right)$ \\
\hline AW190MG & $0,237225 \mathrm{a}$ \\
31B18 & $0,236525 \mathrm{a}$ \\
DK670MG & $0,191742 \mathrm{~b}$ \\
31A25 & $0,167829 \mathrm{c}$ \\
DK747MG & $0,143712 \mathrm{~d}$ \\
30R76 & $0,123491 \mathrm{e}$ \\
\hline
\end{tabular}

Dentro de cada columna valores seguidos de la misma letra no difieren significativamente a un nivel de probabilidad $\mathrm{P}<5 \%$. 


\section{Tasa de Variación de la Digestibilidad in vitro por arriba de la espiga ( $\Delta \mathrm{RMSs})$.}

Tabla 14. Análisis de varianza para $\Delta \mathrm{Divs}$ (\% $i v \%_{\text {altura }}{ }^{-1}$ ) empleando un modelo mixto de 6 híbridos comerciales (efecto fijo), en 4 ambientes (efecto aleatorio).

\begin{tabular}{lccccc}
\hline FV & GL & SC & CM & F & P(\%) \\
\hline A & 3 & 0,020616 & 0,006872 & 2,24 & 12,72 \\
G & 5 & 0,033317 & 0,006663 & 2,16 & 11,37 \\
Bloques (A) & 8 & 0,002897 & 0,000362 & 0,94 & 49,22 \\
A×G & 15 & 0,046260 & 0,003084 & 8,04 & $<0,01$ \\
Error & 40 & 0,015344 & 0,000384 & & \\
\hline
\end{tabular}

La $\Delta$ Divs presenta una interacción $\mathrm{G} \times \mathrm{A}$ significativa $(\mathrm{p}<0,01 \%)$. No se detectaron diferencias significativas para los Genotipos, ni para los ambientes evaluados (Tabla 14). Por lo tanto, se puede asumir que la pérdida de Div de la fracción vegetativa superior de la planta de maíz es independiente del efecto genético y del ambiental, por lo menos dentro de los genotipos evaluados. Tal respuesta es de baja importancia práctica ya que es la sección que menos aporta al rendimiento.

\section{II.4. CONCLUSIONES.}

En este capítulo se discutieron aspectos relacionados con los perfiles de distribución vertical de los parámetros más importantes relacionados con la aptitud forrajera de los híbridos actuales de maíz. La primera hipótesis, referida a la distribución vertical del RMS de caña + hojas, no se rechazó en la mayoría de los casos, salvo en el A2, donde ocurrió un cambio en el perfil de distribución.

La segunda hipótesis describe un modelo de distribución vertical de la Div de la fracción vegetativa, la misma no se rechazó en todos los casos siendo el ajuste del modelo de regresión menos estrecho en el caso del A2.

Los resultados relevantes de este capítulo fueron: a) la similitud en la distribución del rendimiento de los genotipos y su estrecha relación con el ambiente; b) la uniformidad en el contenido de materia seca hasta la altura de inserción de la espiga; c) la variabilidad genética encontrada para la distribución vertical de la calidad nutricional en la fracción vegetativa.

La distribución vertical del RMS de la fracción vegetativa presenta su máximo valor en la base de la planta de maíz y disminuye en forma acrópeta. Esta característica estuvo Luis Ezequiel García Stepien. Tesis de Magister Scientiae en Ciencias Agrarias. Mención en Producción Vegetal. 
fuertemente influenciada por el ambiente, ya que cuando se ve limitada la fuente, el máximo puede darse cerca de la altura de inserción de la espiga.

El contenido de MS se mantuvo constante desde la base hasta la altura de inserción de la espiga, para luego incrementarse hasta la altura de la panoja. Este comportamiento fue similar en todos los híbridos evaluados.

La distribución de la Div en el perfil vertical de la planta de maíz puede ajustarse a un modelo de regresión bisegmentado con su punto de inflexión ubicado a la altura de la espiga, punto de máxima calidad. Esta característica estuvo fuertemente afectada por el ambiente y por el genotipo. El estudio de los patrones de distribución de la Div deberá ser un carácter a tener en cuenta en los programas de mejoramiento. Proponiendo a aquellos híbridos que presenten una distribución más uniforme de la calidad como ideotipos forrajeros. Para no comprometer la calidad nutricional durante el proceso de ensilado, se debería considerar la utilización de mayores alturas de cortes en aquellos genotipos cuyas tasas de variación de la Div sean superiores. 


\section{Capítulo III. RELACIÓN ENTRE EL ÍNDICE DE ESPIGA Y LA CALIDAD FORRAJERA DE LA FRACCIÓN VEGETATIVA EN HÍBRIDOS CON DISTINTO ORIGÉN GENÉTICO.}

\section{III.1. INTRODUCCIÓN.}

La dinámica de la senescencia foliar durante el período de llenado de granos puede variar debido a deficiencias hídricas y nutricionales (Wolfe et al., 1988; Uhart y Andrade, 1995) y/o a variaciones de la relación fuente-destino, esto es la relación entre el abastecimiento de asimilados y el potencial de los granos para captar dichos asimilados (Borrás et al., 2003; Valentinuz y Tollenaar, 2004). Asimismo, se ha establecido que la senescencia foliar también es regulada por una acción hormonal sobre la fuente (Sadras et al., 2000). Aquellos híbridos de maíz que presentan una mayor relación fuente-destino pueden mantenerse verdes en etapas tardías del período de llenado del grano, aspecto que constituye una ventaja respecto de los híbridos que muestran síntomas de senescencia en etapas iniciales de la formación del grano (Rajcan y Tollenaar, 1999). Sadras et al. (2000), observaron un aumento de la senescencia foliar durante la etapa de llenado del grano cuando se impidió la fecundación de la espiga. Thomas y Howarth (2000) proponen que la senescencia foliar puede iniciarse tanto por la carencia o por el exceso de asimilados. Así, el nivel inferior y superior de asimilados acumulados determinan la existencia de una "ventana" de disponibilidad de asimilados, estableciendo que mientras la hoja posea una cantidad de asimilados que se ubique dentro de los niveles inferior y superior, no se iniciarán procesos de senescencia. No obstante, Crafts-Brandner et al., (1984) no encontraron ninguna aceleración de la senescencia foliar cuando la espiga era removida en tres híbridos antiguos de maíz.

Los cambios en la relación fuente-destino durante el llenado del grano son acompañados por cambios en el peso de la caña (Edoka, 2006). La materia seca de la porción vegetativa (Caña + hojas) se incrementa cuando la provisión de asimilados exceden la demanda del grano en crecimiento y se ve disminuida cuando la demanda es mayor a lo producido en la fotosíntesis (Tollenaar y Daynard, 1982; Edoka, 2006).

Un híbrido para silaje no requiere una fuerte translocación desde la caña hacia el grano como en los híbridos graníferos, ya que parte de los azúcares pueden permanecer en la caña sin generar pérdidas de rendimiento ni calidad. De este modo, la caña debería transformarse en un segundo depósito de energía altamente digestible (Gravellier, 1986). 
Zimmer y Wermke (1986), proponen la existencia de variabilidad genética para este carácter, proponiendo básicamente dos modelos de planta de maíz según su partición. El primero, del tipo A, donde el desarrollo de la espiga se debe principalmente a la alta translocación durante el llenado de granos a causa de una reducida asimilación de carbohidratos. Esto produce un rápido decrecimiento en la Div de la caña y el contenido celular rápidamente. El segundo, corresponde al tipo B, donde la asimilación en la caña continua durante el llenado de granos con una menor translocación a la espiga, incrementando el rendimiento del componente vegetativo con una mayor Div de la materia seca.

Considerando la escasa información con respecto a la relación entre ambos tipos de híbridos y su relación con la Div de la materia seca al momento de ensilar, resulta de interés desarrollar estudios que permitan explorar su grado de asociación entre estas variables y su influencia para la generación de nuevos genotipos con una mayor aptitud forrajera para futuros planes de mejora.

\section{Objetivos.}

3.- Determinar el grado de asociación entre el incremento del IE y la calidad nutricional de la fracción vegetativa en híbridos con distinto fondo genético.

\section{Hipótesis.}

C.- El incremento del índice de cosecha afecta en forma inversa la calidad forrajera de la fracción vegetativa en diferentes híbridos de maíz de diverso fondo genético. 


\section{III.2. MATERIALES Y MÉTODOS.}

\section{III.2.1. Datos experimentales.}

El conjunto de datos utilizados para el análisis de este capítulo proviene de 6 híbridos comerciales de maíz, con diverso origen genético, cultivados en 4 A controlados. Una descripción detallada de los ambientes evaluados, los genotipos utilizados y los criterios de cosecha utilizados se encuentran en el capítulo II de la presente tesis.

\section{III.2.2. Mediciones.}

La obtención del peso de planta completa fue el resultado de la sumatoria del peso correspondiente a las espigas y a la fracción compuesta por la caña + hojas. Estas operaciones se realizaron luego de despojar a las plantas de sus correspondientes espigas. El peso ajustado de espiga y caña + hojas conformó el rendimiento de materia verde en $\mathrm{Mg}$ ha $^{-1}$ de cada fracción.

Para determinar el \% MS se muestrearon dos plantas tomadas al azar de cada tratamiento. La muestra de espiga se constituyó por el tercio medio de dos espigas tomadas al azar. La fracción caña + hojas se compuso de dos plantas tomadas al azar, despojadas de sus correspondientes espigas.

Las muestras obtenidas se colocaron en estufa de ventilación forzada con una temperatura de $60^{\circ}$ hasta alcanzar peso constante. Sobre la base del porcentaje de materia seca obtenido de los dos componentes se calculó el rendimiento de materia seca (RMS) de la fracción correspondiente y de la planta completa.

$I E(\%)=R M S e / R M S p c$

Donde:

RMSe: Rendimiento en materia seca de espiga.

RMSpc: Rendimiento en materia seca de la planta completa $=(R M S e+R M S c+h)$.

El análisis de calidad nutricional se realizó únicamente sobre la fracción vegetativa.

Digestibilidad in vitro de la materia seca de caña + hojas $($ Divc $+h)$. 


\section{III.2.3. Análisis estadístico.}

Se realizó un análisis de Correlación de Pearson utilizando el programa estadístico SAS versión 9.2, para determinar la relación existente entre el IE y la calidad forrajera de la fracción vegetativa en híbridos con distinto grado del carácter Stay green.

\section{III.3. RESULTADOS Y DISCUSIÓN.}

Tabla 15. Análisis de correlación entre el IE y la Div de la fracción vegetativa de 6 híbridos, promedio de 4 ambientes.

\begin{tabular}{cccc}
\hline Híbrido & Stay Green & $\mathbf{R}$ & $\mathbf{P}(\%)$ \\
\hline 31B18 & Alto & $-0,720$ & 0,83 \\
30R76 & Medio & $-0,858$ & 0,04 \\
31A25 & Bajo & $-0,615$ & 3,34 \\
DK 747 MG & Alto & $-0,435$ & 15,70 \\
AW 190 MG & Medio & 0,266 & 40,31 \\
DK 670 MG & Bajo & $-0,180$ & 57,60 \\
Promedio & & $-0,338$ & 0,37 \\
\hline
\end{tabular}

Coeficiente de correlación (r); Valor de significancia del modelo (P \%). 


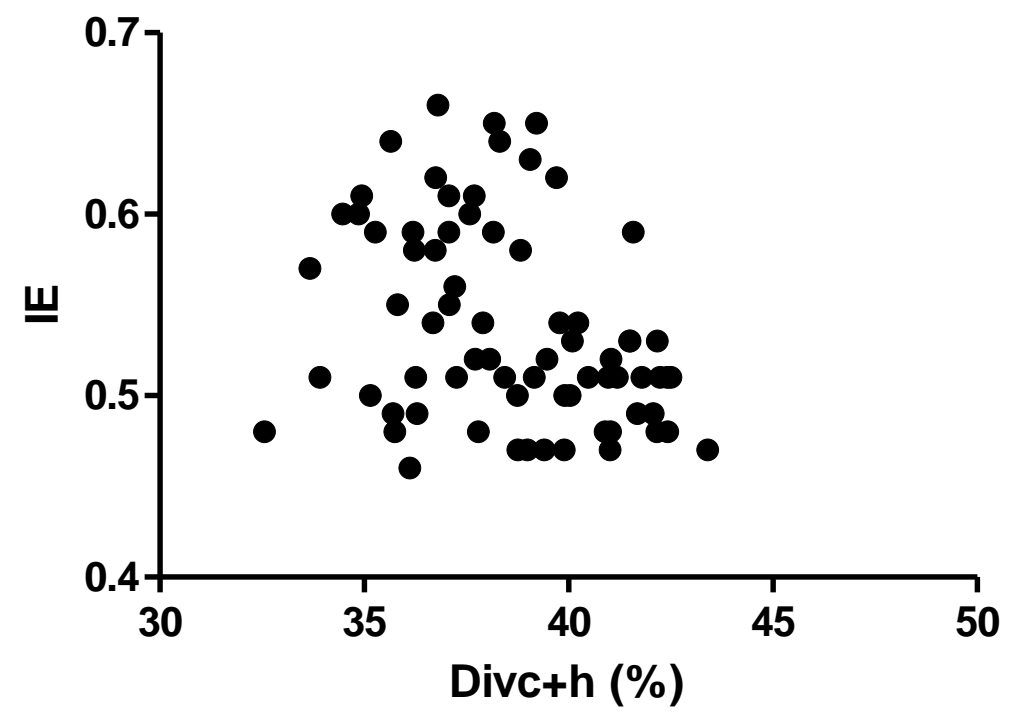

Figura 6. IE vs. Calidad de la fracción vegetativa. Análisis de correlación entre en IE y la Divc+h de 6 híbridos, promedio de 4 ambientes.

La asociación general entre el IE y la Divc $+h$ fue muy baja $(r=-0,338 * *)$ (Figura 6), pese a que el modelo de análisis resultó significativo (Tabla 15). Esto se evidenció al analizar el caso particular de cada uno de los híbridos evaluados, donde se encontró que estas variables se asociaron significativamente en el 50\% de los genotipos evaluados, coincidiendo con los híbridos 31B18, 30R76 y 31A25 (Tabla 15). Estos genotipos se comportaron como los genotipos "tipo A" descriptos por Zimmer y Wermke (1986), coincidiendo a su vez con lo observado por Alessandro (2002) quién apreció una disminución en el contenidos de carbohidratos solubles del tallo a medida que se incrementa la proporción de espiga. Deimun y Bakker (1981) y Vatikkonda y Hunter (1982) afirman que la digestibilidad del componente vegetativo se relaciona con la digestibilidad de la planta completa, pero que no tiene una relación muy estrecha con la proporción de espiga o el rendimiento en grano. Este comportamiento caracterizó a los híbridos DK 747 MG y DK 670 MG, los cuales presentaron un comportamiento definido, como "tipo B" descriptos por Zimmer y Wermke (1986). En este caso, los carbohidratos no estructurales de la fracción vegetativa son utilizados para la síntesis de compuestos estructurales, mantenimiento de la planta o crecimiento del grano y/o de la espiga (Kiniry, et al. 1992). El distinto origen genético de los genotipos, permitió clasificarlos en los dos patrones de distribución de MS, producto de los diferentes programas de selección empleados en los híbridos nacionales. 
Esta notoria diferencia en el comportamiento de los genotipos de diverso origen genético posibilita poner en evidencia la existencia de genotipos que no sufren mermas en la calidad nutricional de la fracción vegetativa al incrementarse el IE, independientemente del grado de Stay green que posean. Estos resultados se complementan con los encontrados por Borrás y Otegui (2001), donde los autores señalan la capacidad diferencial de los genotipos de translocar fotoasimilados desde la fracción vegetativa hacía la espiga. Al analizar el caso particular de los híbridos 31B18, 30R76 y 31A25, se pudo apreciar una alta correlación negativa entre estas variables, siendo menos marcado su efecto en el híbrido 31A25, cuyo carácter Stay green es el más bajo de los tres, según sus obtentores (Tabla 1). Este resultado fue opuesto al esperado, pudiéndose inferir que la merma de la calidad nutricional de la fracción vegetativa y el IE no presentan asociación con el carácter Stay green. Los híbridos 31B18 y 30R76 pudieron deber su pérdida de Divc+h a una mayor translocación de azúcares solubles a la espiga en etapas tempranas del llenado de granos o a un mayor enriquecimiento en celulosa y lignina de la pared celular que el híbrido 31A25. Thomas y Howart (2000), determinaron que aquellos genotipos con un elevado grado de Stay green no siempre muestran altos rendimientos, pudiéndose asociar este carácter a una disminución en el catabolismo de la clorofila o en la removilización de nutrientes.

$31 \mathrm{B18}$

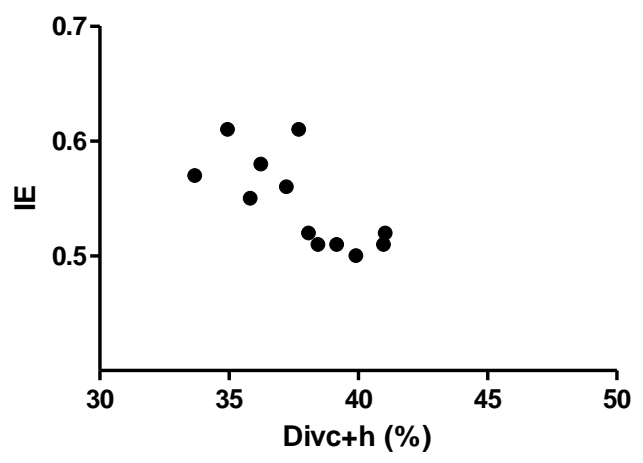

DK 747 MG

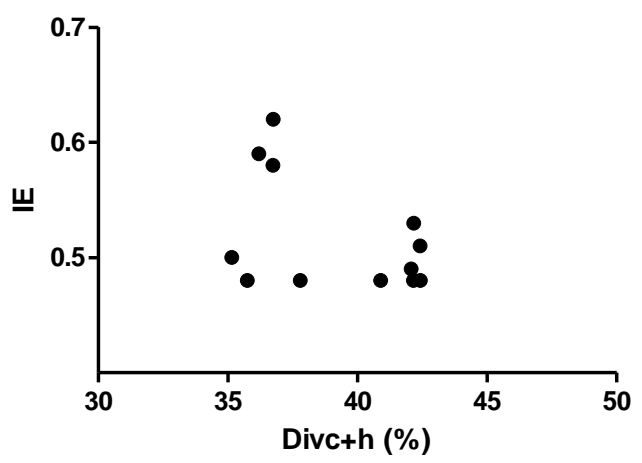


30R76

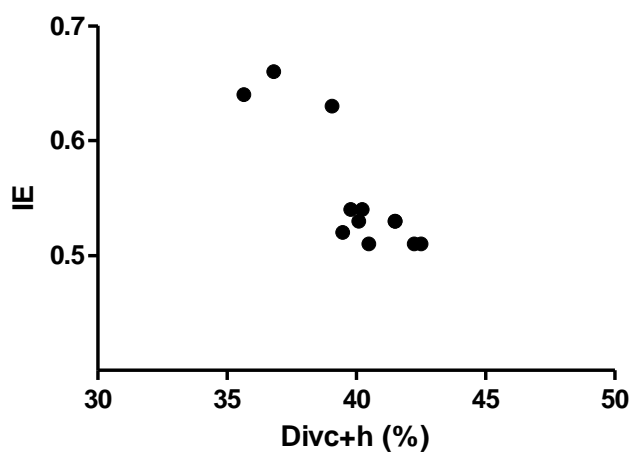

$31 \mathrm{A25}$

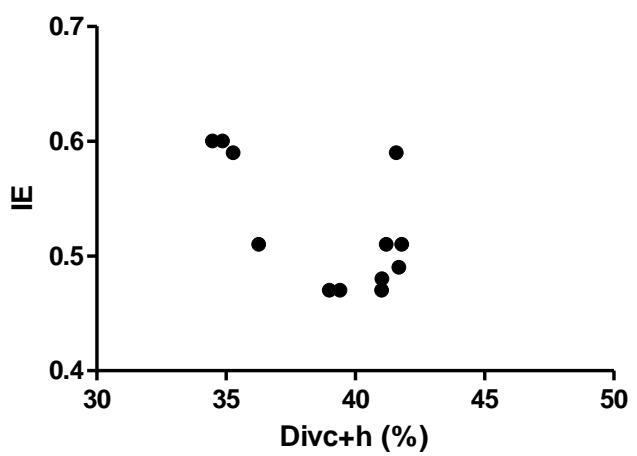

AW 190 MG

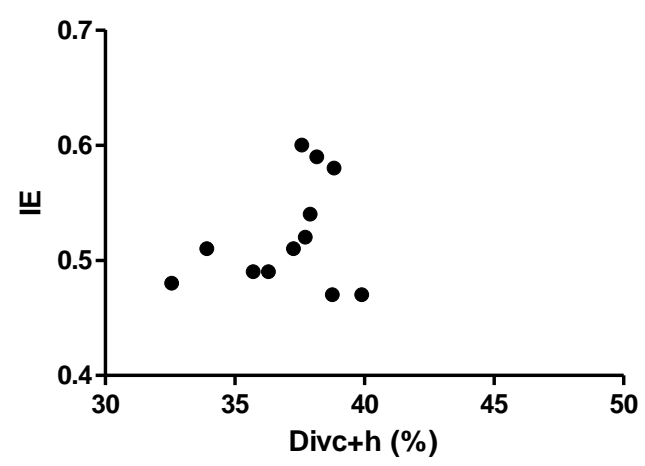

DK 670 MG

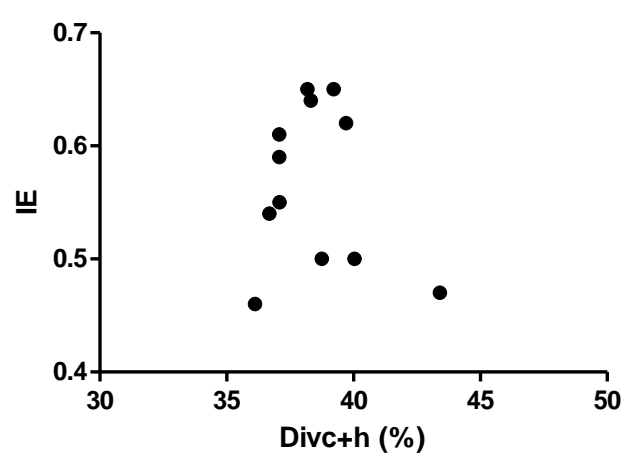

Figura 7. Correlación entre el IE y la Divc+h de la planta de maíz. Valores de 6 híbridos en 4 ambientes con 3 repeticiones.

La respuesta de los híbridos DK 747 MG, AW 190 MG y DK 670 MG sugirieron una posible fuente de variabilidad genética para aquellos híbridos destinados con objetivos forrajeros, en los cuales se busca el incremento del IE sin comprometer la calidad forrajera de la fracción vegetativa. Por lo cual se recomendaría la inclusión de este tipo de genotipos en aquellos programas de selección destinados a la generación de híbridos con destino forrajero. 


\section{III.4. CONCLUSIONES.}

En este capítulo se estableció la asociación entre el IE y la Divc+h entre híbridos de distinto fondo genético. La hipótesis planteada se acepta de manera parcial, ya que se encontraron híbridos en los cuales la Divc+h fue afectada en forma inversa al incremento del IE y por otro lado, también se identificaron genotipos donde no existió ningún tipo de asociación entre estas dos variables. El grado de asociación aparece relacionado al destino final para el cual el híbrido ha sido seleccionado. 


\section{Capítulo IV. LA ALTURA DE CORTE: EFECTO SOBRE LA APTITUD FORRAJERA Y EL RENDIMIENTO DEL MATERIAL A ENSILAR.}

\section{IV.1. INTRODUCCIÓN.}

En nuestro país, el maíz para silaje se cosecha extensivamente a una altura baja, dejando muy poco material remanente. Los productores y contratistas buscan obtener el mayor volumen posible de forraje cosechado (Schneiter y Carrete, 2004), sin importar su calidad, estado de madurez o contenido de humedad. El relieve y el estado del terreno son factores que condicionan la adecuada implementación de esta práctica.

Struik y Deinum (1990) definen a la aptitud técnica como la capacidad que tiene un forraje para ser ensilado. Es decir la capacidad para producir un excelente proceso de conservación. Ésta es máxima cuando las pérdidas en calidad y cantidad durante el proceso de ensilado son mínimas. En un silaje éstas condiciones se logran con un 30 a $40 \%$ MS, proporcionando un ambiente favorable para una correcta fermentación y consecuente conservación del forraje, repercutiendo en una mayor respuesta animal (Lusk, 1978). Bal et al. (1997), consideran que cosechando entre 35 y $38 \%$ MS en planta completa, se maximiza el consumo voluntario, la digestión y producción de leche. Cuando se cosecha la planta entera con un \%MS inferior al $30 \%$, no sólo se reduce el rendimiento, sino también se producen pérdidas por lixiviación por efluentes (Barnett, 1954) y la aparición de bacterias del género Clostridium spp., siendo éstas capaces de convertir a los azúcares solubles y ácidos orgánicos en ácido butírico. El silaje resultante tendrá valores elevados de ácido butírico y pH, pérdidas de materia seca, pobre valor nutritivo, descomposición de proteínas y aminoácidos, generando una brusca caída de la calidad y la palatabilidad del producto final (Bagg, 2001).

Al retrasar el momento de cosecha, cuando el \% MS es superior a $40 \%$, se generan dificultades en la compactación en el silo debido a una inadecuada exclusión del aire, causando una oxidación de la porción más digestible de la planta, con la consiguiente pérdida de azúcares solubles (Darby et al., 2002). La fermentación será deficiente y la temperatura alcanzada elevada (Ma et al., 2006). Los granos resultarán muy secos y duros, por lo que el aprovechamiento en el tracto digestivo del animal podría verse disminuido (Bagg, 2001). Este inconveniente puede ser reducido mediante el procesado en el momento de cosecha (Johnson et al., 1996) con el consiguiente aumento en los costos de cosecha. 
En los híbridos que poseen el carácter Stay green, existe un asincronismo en la velocidad de secado de la espiga y de la caña + hojas. Los granos alcanzarían la madurez cuando la planta entera llegue a tener un $30 \%$ de MS o menos (Thomas, 2001).

La modificación de la altura de corte de la planta es una alternativa factible de implementar con el objeto de aumentar la calidad de los silajes de maíz y lograr balancear el contenido de materia seca del genotipo a ensilar. Esta práctica no siempre traería aparejada una mejora sustancial de la calidad forrajera, ya que algunos autores la recomiendan como relevante en cortes tardíos, entre "1/4 de línea de leche" (final de R5) y madurez fisiológica (R6), debido a que en cortes tempranos no se observan diferencias apreciables en calidad (Schneiter y Carrete, 2004). Por otro lado, la mayor altura de corte incrementa el contenido de materia seca de la planta completa, lo cual puede ser una ventaja ante cosechas anticipadas o maíces inmaduros (Shaver, 2003), o con mayor contenido de humedad como sería de esperar en el caso de los genotipos con Stay green.

De acuerdo al híbrido utilizado, será diferencial el aporte cada fitómero que produce al rendimiento y a la calidad forrajera. Lewis et al. (2004), no recomiendan elevar la plataforma de picado en aquellos híbridos que no compensen las mermas de rendimiento a causa de una escaso incremento de la calidad forrajera, como es el caso de los brown mid rib (bmr-nervadura central marrón). La fecha de siembra y el momento de corte también surgen como variables que condicionarían la calidad y cantidad de forraje a cosechar. Aquí cobra importancia la regulación de la altura de corte como práctica que condiciona la aptitud forrajera del material a ensilar. Este aumento modifica la composición morfológica de la planta, produciendo un incremento en la relación grano/caña + hojas. Por su parte, la calidad de la caña + hojas puede verse favorecida al aumentar la digestibilidad y disminuir el contenido de fibra detergente neutro (FDN) (Lewis, et al., 2004). Wu y Roth, (2003) mostraron que esta práctica trae aparejada una reducción del rendimiento, pero no produce mermas en la producción de leche, o incluso puede llegar a generar incrementos. El aumento en la calidad del silaje genera una mayor eficiencia en la producción láctea (1 de leche/Mg de MS de forraje y 1 de leche/ha) (González Castañeda et al., 2005; Neylon y Kung, 2003). Contrariamente, Lewis et al. (2004), encontraron que dependiendo del híbrido a ensilar, estos aumentos en calidad pueden traducirse o no en aumentos en la producción láctea o cárnica, debido a que puede ocurrir que no logren compensar sus mermas en el rendimiento (MS/ha). 
Romero y Aronna (2004) determinaron que por cada centímetro de aumento en la altura de corte por encima de $15 \mathrm{~cm}$ del suelo se pierden $130 \mathrm{~kg}$ de MS/ha, con un incremento de la calidad. De acuerdo a Satter et al. (2000), el incremento en la altura de corte produce un aumento en la digestibilidad de la fibra (FDND) debido a que la porción más lignificada de la caña queda en el campo. Una reducción en el contenido de FDN tiene un efecto positivo sobre el consumo animal y por lo tanto sobre la producción de carne o leche (Van Olphen et al., 2000). Según Shaver (2003), la regulación de la altura de corte ofrece mayor flexibilidad en el manejo de la calidad del silaje de maíz. En algunas situaciones, aumentar la altura de corte puede producir beneficios al reducir los nitratos, las micotoxinas y/o la erosión del suelo (Shaver, 2003; Wu y Roth, 2003).

De acuerdo a lo presentado anteriormente, y considerando la importancia que posee el desarrollar prácticas de manejo de bajo costo que inciden en la productividad del sistema productivo será sumamente importante determinar la incidencia que tendría la regulación de la altura en la productividad y calidad del silo de maíz de diferentes híbridos.

\section{Objetivos.}

4.- Determinar las potenciales variaciones que se producirían por efecto de cortes a diferentes alturas en la materia seca y la calidad forrajera del material a ensilar.

\section{Hipótesis.}

D.- Las pérdidas de rendimiento producidas por elevar la altura de corte, son compensadas con una mejor aptitud técnica en aquellos híbridos que presentan un elevado grado de Stay green. 


\section{IV.2. MATERIALES Y MÉTODOS.}

\section{IV.2.1. Datos experimentales.}

Seis híbridos comerciales de maíz, con diverso origen genético, fueron cultivados en 4 ambientes controlados ubicados en el cinturón lechero que rodea al Gran Buenos Aires. Los ambientes evaluados, los genotipos utilizados y los criterios de cosecha empleados se encuentran detallados en el capítulo II de la presente tesis.

\section{IV.2.2. Mediciones.}

Se evaluaron las fracciones espiga y caña + hojas por separado, de los mismos seis híbridos, vinculándose estos valores mediante el IE para obtener los valores de planta completa. Para simular las tres alturas de corte, se cortaron dos cañas por bloque a partir de $\operatorname{los} 5,35$ y $65 \mathrm{~cm}$ de altura.

La obtención del peso de planta completa fue el resultado de la sumatoria del peso correspondiente a las espigas y a la fracción compuesta por la caña + hojas. Estas operaciones se realizaron luego de despojar a las plantas de sus correspondientes espigas. El peso ajustado de espiga y caña + hojas conformó el rendimiento de materia verde en $\mathrm{Mg}$ ha $^{-1}$ de cada fracción.

Luego, las muestras fueron molidas mediante un molino de cuchillas con malla de 1 $\mathrm{mm}$, para poder determinar las variables relacionadas con la calidad:

Digestibilidad in vitro de la materia seca de espiga (Dive).

Digestibilidad in vitro de la materia seca de caña + hojas $($ Divc $+h)$.

Digestibilidad in vitro de la materia seca de planta completa (Divpc).

$$
\text { Divpc }=(I E \times D i v e)+((1-I E) \times D i v c+h)
$$




\section{IV.2.3. Análisis estadístico.}

Se empleó un diseño de bloques completos aleatorizados con tres repeticiones. Las fuentes de variación corresponden a ambientes (4 años-localidades), anidados en ambientes, híbridos, alturas de corte y las respectivas interacciones. Se considerará al ambiente como variable aleatoria y a las alturas de corte e híbridos como variables de efectos fijos, lo cual generará un modelo mixto, a resolver de acuerdo a Mc Instosh, (1983):

$$
\mathrm{Y}_{\alpha \gamma \delta}=\mu+\alpha+\beta(\alpha)+\gamma+\delta+\alpha \times \gamma+\alpha \times \delta+\gamma \times \delta+\alpha \times \gamma \times \delta+\varepsilon_{\alpha \gamma \delta}
$$

Donde:

$\boldsymbol{\mu}=$ Media general del ensayo para la variable considerada.

$\boldsymbol{\alpha}=$ Efecto del ambiente.

$\boldsymbol{\beta}(\boldsymbol{\alpha})=$ Efecto de bloque anidado en ambientes.

$\gamma=$ Efecto del híbrido.

$\boldsymbol{\delta}=$ Efecto de la altura de corte.

$\boldsymbol{\alpha} \times \boldsymbol{\gamma}=$ Interacción ambiente $\times$ híbrido.

$\boldsymbol{\alpha} \times \boldsymbol{\delta}=$ Interacción ambiente $\times$ altura de corte.

$\boldsymbol{\gamma} \times \boldsymbol{\delta}=$ Interacción híbrido $\times$ altura de corte.

$\boldsymbol{\alpha} \times \boldsymbol{\gamma} \times \boldsymbol{\delta}=$ Interacción ambiente $\times$ híbrido $\times$ altura de corte.

$\boldsymbol{\varepsilon}_{\boldsymbol{\alpha} \gamma \delta}=$ Error experimental.

Los datos se analizaron la utilización del procedimiento GLM del programa estadístico SAS versión 9.2. Para las comparaciones entre medias se utilizó del test de Diferencias Mínimas Significativas (DMS) con un nivel de significancia de $p<0,05$. 


\section{IV.3. RESULTADOS Y DISCUSIÓN.}

Tabla 16. Efecto e la Altura de corte sobre la aptitud forrajera.

\begin{tabular}{|c|c|c|c|c|c|}
\hline FV & IE & $\%$ MSpc & RMSpc & Divpc & RMSDpc \\
\hline A & $0,222525 * *$ & $394,67 * *$ & $939615882 * *$ & $296,26^{* *}$ & $306563355 * *$ \\
\hline $\mathrm{G}$ & $0,014847 *$ & $77,61 \mathrm{~ns}$ & $7757492 \mathrm{~ns}$ & $104,30 * *$ & $2382127 \mathrm{~ns}$ \\
\hline $\mathrm{H}$ & $0,196068 * *$ & $230,41 * *$ & $138542587 * *$ & $515,76^{* *}$ & $20641950 * *$ \\
\hline Bloques (A) & $0,001212 * *$ & $3,056^{* *}$ & $5868564 * *$ & $3,26^{*}$ & $2197557 * *$ \\
\hline$A * G$ & $0,003666^{* *}$ & $27,01 * *$ & $9304198 * *$ & $14,89 * *$ & $4680379 * *$ \\
\hline$A * H$ & $0,004824 * *$ & $0,57 \mathrm{~ns}$ & $242681 *$ & $6,85 * *$ & $109260 * *$ \\
\hline $\mathrm{G}^{*} \mathrm{H}$ & $0,000066 \mathrm{~ns}$ & $0,53 \mathrm{~ns}$ & 132599ns & $0,30 \mathrm{~ns}$ & $31765 n s$ \\
\hline $\mathrm{A} * \mathrm{G} * \mathrm{H}$ & $0,000114 \mathrm{~ns}$ & $0,27 \mathrm{~ns}$ & $85437 \mathrm{~ns}$ & $0,44 \mathrm{~ns}$ & $20222 \mathrm{~ns}$ \\
\hline
\end{tabular}

Resumen de los cuadrados medios provenientes de los Análisis de varianza del ensayo AmbientexGenotipoxAltura de Corte, para las variables: Índice de Espiga (IE),Contenido de Materia Seca de planta completa (\%MSpc), Rendimiento en Materia Seca de planta completa (RMSpc), Digestibilidad in vitro de planta completa (Divpc), Rendimiento en Materia Seca Digestible de planta completa (RMSDpc). Test F: ** significativo al 1\%; * significativo al 5\%; ns no significativo.

\section{Contenido de materia seca de la planta completa (\%MSpc).}

Todos los genotipos se cosecharon a igual contenido de materia seca de planta completa, lo cual posibilitó comparar el resultado de modificar la altura de corte. La regulación de la altura de corte resultó ser una herramienta válida para corregir el \%MSpc, no habiendo diferencias apreciables entre los híbridos (Tabla 16). Esto pudo deberse a que en estadios tempranos del llenado de granos no pueden apreciarse tales diferencias entre los genotipos. El ambiente generó distintos escenarios de evaluación, cobrando importancia la altura de corte, como factor regulador del \% MSpc. Se obtuvieron incrementos promedio en la \% MSpc de 2 y 4 puntos, al subir la altura de corte de 5 a $35 \mathrm{~cm}$ y de 5 a $65 \mathrm{~cm}$ respectivamente (Tabla 17). Esta medida cobró relevancia en aquellos ambientes donde el IE se vio disminuido, como lo fue el A2 y A4 (Tabla 19), producto de las fechas de siembra y las mayores temperaturas durante el período de crecimiento vegetativo. Estos factores produjeron un desbalance entre la dureza del grano y el contenido de MS óptimo para que el material sea conservado. Esto se debió a que en este estado de desarrollo ( $35 \% \mathrm{MSpc}$ ), la fracción reproductiva posee un contenido de materia seca superior que en ambientes normales (mayor a 55\%), con la consecuente mayor dureza de grano, mientras que en la fracción vegetativa, presenta un \% MS mucho menor (cercano a $20 \%$ ) y su aporte se ve incrementado, (menor IE). 
Tabla 17. Medias de las tres alturas de corte para las variables: Índice de Espiga (IE), Contenido de Materia Seca de planta completa (\%MSpc), Digestibilidad in vitro de planta completa (Divpc), Rendimiento en Materia Seca de planta completa (RMSpc), de seis híbridos en los cuatro ambientes.

\begin{tabular}{ccccc}
\hline Altura de Corte (cm) & IE (\%) & \% MSpc (\%) & Divpc (\%) & RMSpc (kg ha $\left.^{-1}\right)$ \\
\hline 5 & $53,81 \mathrm{c}$ & $34,96 \mathrm{c}$ & $63,24 \mathrm{c}$ & $18085 \mathrm{a}$ \\
35 & $58,28 \mathrm{~b}$ & $36,71 \mathrm{~b}$ & $65,76 \mathrm{~b}$ & $16782 \mathrm{~b}$ \\
65 & $64,21 \mathrm{a}$ & $38,54 \mathrm{a}$ & $68,59 \mathrm{a}$ & $15312 \mathrm{c}$ \\
\hline
\end{tabular}

Medias con la misma letra no son significativamente diferentes con un alfa del 5\%. V.C.C.: 1,97756.

\section{Índice de Espiga (IE).}

La espiga produce el mayor aporte al contenido de MS y a la calidad nutricional de la planta de maíz. Su contribución respecto del total de la planta puede verse reflejada en el IE. Si bien el IE está significativamente influenciado por el ambiente, su contribución al resto de la planta puede ser modificada mediante la regulación de la altura de corte. Los resultados mostraron incrementos promedio en el IE de 6 y 10 puntos, al subir la altura de corte de 5 a $35 \mathrm{~cm}$ y de 5 a $65 \mathrm{~cm}$ respectivamente (Tabla 17). Esto demostró que no sólo producen cambios en el perfil nutricional del híbrido a ensilar, sino también en el balance de su contenido de materia seca. Alessandro (2002) encontró una elevada asociación positiva entre la proporción de espiga y el \%MSpc. Los genotipos evaluados difirieron significativamente en su proporción de espiga, no relacionándose la misma con grado del carácter Stay green que poseían.

\section{Digestibilidad in vitro de la planta completa (Divpc).}

La calidad nutricional de la planta de maíz se vio condicionada tanto por factores ambientales, genéticos como de manejo, así también como por la interacción $\mathrm{A} \times \mathrm{H}$ (Tabla 16). Es importante remarcar la relevancia que tiene el efecto ambiental, lo cual puede verse reflejado en el CM (Tabla 16). En ambientes más cálidos (A2), como puede darse en siembras tardías, la Divpc es menor debido al efecto negativo que ejerce la temperatura 
sobre la calidad del material a ensilar. Diversos autores (Graybill et al., 1991; Buxton, 1996) describen el efecto negativo del atraso de la fecha de siembra y su relación con el aumento de la temperatura como uno de los más influyentes sobre la calidad del forraje. A su vez, la ganancia en Divpc por incrementar la altura de corte es menor en este tipo de ambientes (Tabla 19), ya que a la menor calidad de la fracción vegetativa se le suma el menor aporte del IE por la merma de la oferta ambiental (Andrade et al., 1996). Para los ambientes evaluados, en general se aprecian ganancias en la Divpc de 3 y 5 puntos, al subir la altura de corte de 5 a $35 \mathrm{~cm}$ y de 5 a $65 \mathrm{~cm}$ respectivamente (Tabla 17). Estas ganancias son de suma importancia a la hora de formular las raciones de los animales que se desean alimentar, ya que los incrementos logrados en la conversión animal son mayores por cada incremento en la digestibilidad, que por aumentos proporcionales en el rendimiento (Neylon y Kung, 2003; Wu y Roth, 2003; González Castañeda et al., 2005). El efecto Genético es significativo (Tabla 16), aunque no exista una asociación entre el grado del carácter Stay green y la Divpc. La calidad nutricional se asoció significativamente con el IE $\left(\mathrm{r}=0,77^{* *}\right)$ (Tabla 18), siendo no significativa su relación con la Divc+h. Por lo tanto, los híbridos con mayor IE fueron aquellos con mayor Divpc, independientemente de su grado de Stay green.

Tabla 18. Aporte del IE a la Divpc y a la Divcth de la planta de Maíz. Matriz de correlaciones entre: Divpc; Divc+h e IE.

\begin{tabular}{l|cc}
\hline & Divpc & Dive+h \\
\hline Divc+h & $0,2253 \mathrm{~ns}$ & \\
IE & $0,7744^{* *}$ & $-0,3380^{* *}$ \\
\hline
\end{tabular}

** significativo al 1\%; * significativo al 5\%; ns no significativo.

\section{Rendimiento en materia seca de la planta completa (RMSpc).}

Al aumentar la altura de corte se produjeron mermas significativas en el RMSpc. Al incrementar la altura de corte de 5 a 35 y de 5 a $65 \mathrm{~cm}$, se perdió en promedio 7,21\% y 15,35\% del RMSpc respectivamente (Tabla 17). El ambiente generó diferencias significativas entre los tratamientos, registrando los mayores rendimientos de planta completa al retrasarse la fecha de siembra. Este comportamiento coincidió con lo descripto 
por Fairey (1983) y Graybill et al. (1991) hasta una fecha por después de la cual el rendimiento cae. El ambiente tardío (A2), caracterizado por una mayor temperatura media $\left(23,6^{\circ} \mathrm{C}\right.$ período siembra-R1) (Tabla 2), fue el que generó los mayores RMSpc. Al no producirse limitaciones hídricas, estas condiciones podrían haber favorecido el crecimiento vegetativo, generando plantas más altas y con mayor área foliar (Tollenaar et al., 1979; Andrade et al., 1996), por lo que a igualdad de altura de corte la pérdida de rendimiento registrada fue menor. No se encontraron diferencias entre los genotipos evaluados en sus rendimientos logrados. La falta de asociación entre el grado de Stay green de los híbridos y el rendimiento ante distintas condiciones ambientales, ya fue planteada por diversos autores. Mientras algunos señalan la posibilidad que la retención del color verde de las hojas no se encuentre asociado a una concomitante mantención de su capacidad fotosintética (Edmeades et al., 1997; Delard Rodríguez, 2006), otros más cercanos a la realidad de los híbridos nacionales (Andrade et al., 1996; Borrás y Otegui, 2001), lo relacionan a una limitación por destino que no permite una mayor translocación de esa mayor fuente que poseen los híbridos Stay green.

\section{Rendimiento en materia seca digestible de la planta completa (RMSDpc).}

El ambiente generó diferencias significativas entre los RMSDpc obtenidos, aunque no se encontraron diferencias entre genotipos. A medida que se aumentó la altura de corte, se disminuyó el RMSDpc. Al cortar a $35 \mathrm{~cm}$ se está perdiendo en promedio un 4,4\% del RMSpc y al cortar a $65 \mathrm{~cm}$ se pierde un $9,4 \%$ (Tabla 17). Al evaluar el porcentaje de pérdida de RMSDpc al elevar la altura de corte, estos son similares en todos los ambientes. Debido a que los mayores rendimientos obtenidos en los ambientes más cálidos (A2 y A4), se contrarrestan con la menor calidad, ocurriendo lo contrario en la fecha más temprana (A1) (Tabla 19). Por lo tanto, en los ambientes A2 y A4, se pueden lograr incrementos en la calidad del forraje a ensilar mediante la elevación de la altura de corte, sin producir mayores pérdidas de rendimiento. 
Tabla 19. Medias de las variables: Índice de Espiga (IE), Rendimiento en Materia Seca de planta completa (RMSpc), Digestibilidad in vitro de planta completa (Divpc), rendimiento en materia seca digestible de planta completa (RMSDpc) de seis híbridos para los cuatro ambientes.

\begin{tabular}{ccccc}
\hline Ambiente & IE (\%) & RMSpc (kg ha-1) & Div (\%) & RMSDpc (kg ha-1) \\
\hline 1 & $66,59 \mathrm{a}$ & $17355 \mathrm{~b}$ & $65,39 \mathrm{a}$ & $11369 \mathrm{~b}$ \\
2 & $53,85 \mathrm{c}$ & $21211 \mathrm{a}$ & $60,85 \mathrm{c}$ & $12858 \mathrm{a}$ \\
3 & $61,42 \mathrm{~b}$ & $12337 \mathrm{c}$ & $63,70 \mathrm{~b}$ & $7919 \mathrm{c}$ \\
4 & $53,19 \mathrm{c}$ & $21360 \mathrm{a}$ & $63,01 \mathrm{~b}$ & $13221 \mathrm{a}$ \\
\hline
\end{tabular}

Medias con la misma letra dentro de las columnas no son significativamente diferentes con un alfa del $5 \%$. V.C.C.: $1,97756$.

La regulación de la altura de corte resultaría ser una herramienta útil para corregir el \% MSpc, no habiendo diferencias apreciables entre los híbridos utilizados con y sin Stay green. Su implementación se asoció en mayor medida con: a) el momento de picado y con b) la variabilidad ambiental. Al momento de picado un retraso posterior al $40 \% \mathrm{MSpc}$, elevar la plataforma de picado resultaría ser una herramienta útil para incrementar la calidad nutricional del material a ensilar, no obstante, trae aparejado inconvenientes en el proceso de conservación, comprometiendo así la ganancia de calidad obtenida. Por lo cual no se recomendaría elevar la plataforma ante cosechas posteriores a la ventana de picado. Por el otro lado ante cosechas anticipadas al $30 \% \mathrm{MSpc}$, elevar la plataforma podría ser una medida útil para incrementar el \%MSpc mediante el aporte del IE y de la fracción superior de la planta. De esta manera se lograrían disminuir las perdidas por lixiviación de efluentes.

b) $\mathrm{Al}$ producirse el momento optimo de picado (35\% MSpc), en aquellos ambientes donde la fracción reproductiva se vio disminuida debida a la menor oferta ambiental, se produce un desbalance en el \%MSpc de los materiales a ensilar. En estos ambientes se llega al 35\% MSpc con un grano más avanzado en su madurez (mayor dureza), mientras que en la fracción vegetativa ocurre lo contrario, comparativamente con ambientes normales. Al elevar la altura de picado en estos ambientes, se podría incrementar el $\%$ MSpc sin retrasarnos en la madurez de la espiga, logrando un mejor balance de la planta, sin comprometer su aptitud para ser ensilada. Elevar la altura de corte traería aparejado incrementos en la Divpc, pero su implementación se ve justificada en aquellos ambientes donde el efecto de la temperatura produce mayores crecimientos vegetativos y una disminución de la calidad forrajera. 


\section{IV.4. CONCLUSIONES.}

En este capítulo se estableció la importancia de la regulación de la altura de corte como una herramienta válida para corregir y balancear el \% MS de los distintos componentes de la planta y así lograr las mejores condiciones para la preservación de la calidad forrajera. La hipótesis planteada fue rechazada, ya que no se detectaron diferencias apreciables entre los híbridos utilizados con y sin Stay green.

No obstante, elevar la altura de corte, podría ser una herramienta útil para corregir el \%MSpc y así lograr una mejor aptitud técnica del forraje. Su implementación se asoció en mayor medida con el momento de picado y con la variabilidad ambiental que con el genotipo a ensilar. 


\section{Capítulo V. CONCLUSIONES GENERALES}

En el capítulo II, se discutieron aspectos relacionados con los perfiles de distribución vertical de los parámetros más importantes relacionados con la aptitud forrajera de los híbridos actuales de maíz. La primera hipótesis enuncia: "El rendimiento en materia seca de la fracción vegetativa presenta valores máximos en la base de la planta, disminuyendo hacia la sección apical de la misma”. La misma fue aceptada en la mayoría de los casos, salvo en el ambiente 2 donde ocurrió un cambio en el perfil de distribución. En el caso de la segunda hipótesis: "El aporte de los estratos de la fracción vegetativa a la calidad nutricional $(\mathrm{D} i v \mathrm{c}+\mathrm{h})$ sigue una distribución centrípeta con valores máximos en la fracción que porta a la espiga", fue aceptada en todos los casos. Los resultados relevantes de este capítulo fueron: a) la similitud en la distribución del rendimiento y su estrecha relación con el ambiente; b) la uniformidad en el contenido de materia seca hasta la altura de inserción de la espiga; c) la variabilidad genética encontrada para la distribución vertical de la calidad nutricional en la fracción vegetativa de híbridos de maíz.

En el capítulo III, se estableció la existencia o no de asociación entre el IE y la Divc + h entre híbridos de distinto fondo genético. La hipótesis planteada fue: "El incremento del índice de cosecha afecta en forma inversa la calidad forrajera de la fracción vegetativa en diferentes híbridos de maíz de diverso fondo genético". La misma se aceptó de manera parcial, ya que se encontraron híbridos en los cuales la Divc+h fue afectada en forma inversa al incremento del IE y por otro lado, también se identificaron genotipos donde no existió ningún tipo de asociación entre estas dos variables.

En el capítulo IV, se estableció la importancia de la regulación de la altura de corte como una herramienta válida para corregir y balancear el \% MS de los distintos componentes de la planta y así lograr las mejores condiciones para la preservación de la calidad forrajera. La hipótesis planeada fue: "Las pérdidas de rendimiento producidas por elevar la altura de corte, son compensadas con una mejor aptitud técnica en aquellos híbridos que presentan un elevado grado de Stay green". La misma fue rechazada, ya que no se detectaron diferencias apreciables entre los genotipos evaluados con y sin Stay green. No obstante, elevar la plataforma de picado resultaría ser una herramienta útil para corregir el \%MSpc. Su implementación se asoció en mayor medida con: a) el momento de picado y con b) la variabilidad ambiental.

En síntesis, se pudo determinar que atributos como los perfiles de distribución vertical del rendimiento $\left(\mathrm{kg} \mathrm{MS} \mathrm{ha}^{-1}\right)$ y la calidad nutricional de la fracción vegetativa, así 
como también la relación entre el IE y la Divc+h, son fuentes de variabilidad criterios de selección a tener en cuenta en planes de mejoramiento destinados a obtener genotipos sileros.

La escasa variación encontrada para el grupo de genotipos evaluados, es meritoria para discutir sobre la definición y clasificación de los maíces graníferos, sileros, doble propósito con genes incorporados de efecto cuali-cuantitativo y de diferentes grupos heteróticos que en silaje escasamente se ha estudiado. 


\section{Capítulo VI. INVESTIGACIONES FUTURAS.}

En función de los resultados obtenidos en el presente trabajo se podría continuar avanzando en líneas de investigación relacionadas con: a) Caracterización de los perfiles de distribución de azúcares solubles en la fracción vegetativa y su variabilidad genéticoambiental, con el fin de obtener información acerca de la translocación de fotoasimilados; b) Análisis de los cambios que se producen en los perfiles de distribución de la calidad forrajera a lo largo de la ventana de picado en aquellos genotipos con menor $\Delta \mathrm{D} i v$ en el momento óptimo de picado (35\% MSpc); c) Búsqueda en los bancos de germoplasma de genotipos con menor $\Delta \mathrm{D} i v$ y baja relación entre el IE y la pérdida de calidad forrajera de la fracción vegetativa, para ser utilizados en futuros planes de mejoramiento.

Esta información sumada a la generada en esta tesis podría ser de gran utilidad en programas de mejoramiento cuyos objetivos sean el desarrollo de genotipos con mayor aptitud forrajera. A su vez, se desprenden prácticas de manejo de gran utilidad para los productores agropecuarios que hacen uso del maíz como reserva forrajera de excelente calidad. 


\section{BIBLIOGRAFÍA.}

Adugna,T. \& F., Sundstol. 1999. Morphological fractions of maize stover harvested at different stages of grain maturity and nutritive value of different fractions of the stover. Animal Feed Science and Technology. 81:1-16.

Alessandro, M. S. 2002. Variabilidad y parámetros genéticos en caracteres morfofisiológicos de maíz (Zea mays L.) para silaje. Tesis de Magister Scientiae en Mejoramiento Genético Vegetal. UNR. 107pp.

Alessandro, M. S.; Carrete, J. R. y Rimieri, P. 2005. Calidad y degradabiliad de la materia seca acumulada en la planta entera y en el tallo de maíz para silaje. VIII Congreso Nacional de Maíz.

Allen, M. S.; J. G., Coors \&, G. W., Roth. 2003. Corn silage. Silage science and technology, Agronomy Monograph. No. 42. 547-608.

Andrade, F.; A., Cirilo; S., Uhart y M., Otegui. 1996. Ecofisiología del cultivo de maíz. Editoral Médica Panamericana, pp:292.

Bagg, J. 2001. Harvesting corn silage at the right moisture. Disponible en: http://www.omafra.gov.on.ca/english/crops/facts/07-047.htm. Ontario Ministry of Agriculture, Food, and Rural Affairs, Queen's Park, ON, Canada. Archivo 5 Mar. 2008

Bal, M. A.; Coors, J. G. \&, R. D., Shaver. 1997. Impact of the maturity of corn for use as silage in the diets of dairy cows on intake, digestion, and milk production. J. Dairy Sci. 80:2497-2503.

Barnett, A. J. G. 1954. Silage fermentation. Academic Press, New York.

Barrière, Y.; D., Alber; O., Dolstra; C., Lapierre; M., Motto; A., Ordas; J., Van Waes; L., Vlasminkel; C., Welcker \&, J.P., Monod. 2005. Past and prospects of forage maize breeding in Europe. 1. The grass cell wall as a basis of genetic variation and future improvements in feeding value. Maydica 50: 259-274. 
Bertoia, L. M. 2000. Evaluación de la aptitud forrajera de probadores graníferos mediante compuestos de maíz (Zea mays L.) con distintos niveles de selección. Facultad de Ciencias Agrarias. UNLZ. Tesis de Magister Scientiae. Área Producción Vegetal. UBA.

Bertoia, L. M. 2012. Análisis de la interacción genotipo-ambiental de la aptitud forrajera en maíz (Zea mays L.). Facultad de Ciencias Agrarias. UNLZ. Tesis de Doctorado en Ciencias Agrarias. Área Producción Vegetal. UNLP.

Borrás, L. \& M. E. Otegui. 2001. Maize kernel weight response to post-flowering sourcesink ratio. Crop Sci. 41(6) 1816-1822.

Borrás, L.; G.A Maddonni \&, M.E Otegui. 2003. Leaf senescence in maize hybrids: plant population, row spacing and kernel set effects. Field Crops Research. 82:13-26.

Bosch, L.; A., Ferret; F., Casañas; A.M., Verdú \& F. Nuez. 1989. Comparison of stay green and non stay green maize hybrids for forage use A: XII Eucarpia congress, 27 feb-4 march 1989. Germany. pp. 5-17.

\section{Bosch, L.; A.M., Verdú; A., Ferret; Casañas, F.; J. Plaixats; E. Albanell \& F. Ñuez.} 1990. Delayed leaf senescence (stay green) and digestibility in maize. XVth Congress Maize and Sorghum.Baden, Austria .June 1990 pp.299-304.

Brero, R. A. 1974. Valor biológico del silaje. Boletin interno de divulgacion $\mathrm{N}^{\circ} 27$. EERA INTA Rafaela.

Brero, R. A. 1979. Silajes, sus distintos niveles de calidad. Información para extensión $\mathrm{N}^{\circ}$ 8. EERA INTA Rafaela.

Buxton, D. R. 1996. Quality-related characteristics of forages as influenced by plant environment and agronomic factors. Animal Feed Science Technology. 59:37-49 
Crafts-Brandner, S.J.; F.E., Below; J.E., Harper \&, R.H., Hageman. 1984. Differential senescence of maize hybrids following ear removal. I. Whole Plant. Plant Physiology. 74:360-367.

Darby, H. M. \& J. G., Laurer. 2002. Harvest date and hybrid influence on corn forage yield, quality, and preservation. Agronomy Journal. 94:559-566.

Deimun, B. \& J. J., Bakker. 1981. Genetics differens in digestibility of forage maize hybrids. Netherlands. Journal Agricultural Science. 29: 93-98.

Delard Rodríguez, G. 2006. Senescencia foliar retardada del maíz en condiciones de estres hídrico. Tesis de Magister Scientiae. Pontificia Univercidad Católica de Chile.

Dhillon, B. S.; C., Paul; E., Zimmer; P. A., Gurrath; D., Klein \&, W. G., Pollmer. 1990. Variation and covariation in stover digestibility traits in diallel crosses of maize. Crop Sci., 30 (5), 931-936.

Edmeades, G.O.; M., Bänziger; H.R., Mickelson \&, C.B, Peña Valdivia. 1997. Developing drought-and low N- tolerant maize. $\mathrm{p}$ 131-222. In Proceedings of a Symposium. El Batán, México 25-29 March. 1996. CIMMYT, México D.F., México.

Edoka, P. 2006. Influence of leaf area development of early and mid-early maturity varieties of silage maize on dry matter yield and forage quality. Zertifizierter Dokumentenserver der Humboldt-Universität zu Berlin.

Fairey, N. A. 1980. Hybrid maturity and the relative importance of grain and stover for the assessment of the forage potential of maize genotypes grown in marginal and nonmarginal environments. Canadian Journal Plant Science. 63:157-168.

Fairey, N. A. 1983. Yield, quality and development of forage maize as influenced by dates of planting and harvesting. Canadian Journal Plant Science. 63:157-168. 
González Castañeda, F.; A., Peña Ramos; G., Núñez Hernández y C. A., Jiménez González. 2005. Efecto de la densidad y altura de corte en el rendimiento y calidad del forraje de maíz. Revista Fitotecnia Mexicana. Vol. 28, (4): pp. 393-397.

Graybill, J. S.; W. J., Cox \&, D. J., Otis. 1991. Yield and quality of forage maize as influenced by hybrid, planting date, and plant density. Agronomy journal. 83:559-564.

Gravellier, P. 1986. L'ensilage technique pour produire mieux. Maiscope. Decembre. No.19, pp.19-27.

Gunn, R. E. 1975. Breeding maize for forage production. Proceedings of 8th Congress of maize and sorghum section of Eucarpia. Paris, Verailles, pp. 37-58.

Johnson, L.; J. H., Harrison; K. A., Loney; D., Bengen; R., Bengen; W. C., Mahanna; D., Sapienza; W., Kezar; C., Hunt; T., Sawyer \&, M., Bieber. 1996. Effect of processing of corn silage prior to ensiling on milk production, component yield, and passage of corn grain into manure. Journal Dairy Science. 79(Suppl. 1):149.(Abstr.).

King, C. C., Jr.; D. L. Thompson \&, J. C., Burns. 1971. Plant component yield and cell contents of an adapted and a tropical corn, Zea mays L. Crop Science. 12:446-449.

Kiniry, J. R.; C. R., Tischler; W. D., Rosenthal \&, T. J., Gerik. 1992. Nonstructural carbohydrate utilization by sorghum and maize shaded during grain growth. Crop Science. 32:131-137.

Lewis, A. L.; W. J., Cox \&, J. H., Cherney. 2004. Hybrid, maturity, and cutting height interactions on corn forage yield and quality. Agronomy Journal. 96:267-274.

Lusk, J. W. 1978. The use of preservatives in silage productions. In M.E. McCullough (ed.) fermentation of silage - A review. National Feed Ingredients Association. Des Moines, IA. pp. 201-232

Ma, B. L.; K. D., Subedi; D. W., Stewart \&, L. M., Dwyer. 2006. Dry Matter accumulation and silage moisture changes after silking in Leafy and Dual-Purpose corn hybrids. Agronomy Journal. 98:922-929. 
McIntosh, M.S. 1983. Analisis of combined experiments. Agron. Journal. 75:153-155

Miralles, D. J; C. F. Dominguez \&, Slafer, G. A. 1996. Relarionship between grain growth and postanthesis leaf area. Duration in dwarf, semidwarf and tall isogenic lines of wheat. Journal. Agiwiomy \& Crop Science 177, 115-122.

Nevens, W. B. 1933. Types and varieties of corn silage. University of Illinois Agricultural Experiment Station Bulletin, pp. 391.

Nevens, W. B. \& G. H., Dungan. 1942. Yield of corn hybrids harvested for silage: A method to determine best time to harvest. University of Illinois Agricultural Experiment Station Bulletin, pp. 494.

Neylon, J. M. \& L., Kung, Jr. 2003. Effects of cutting height and maturity on the nutritive value of corn silage for lactating cows. Journal Dairy Sience. 86:2163-2169.

Pedersen, J. F. 1996. Annual forages: New approaches for C-4 forages. Progress in new crops. ASHS Press, Alexandria, VA. J. Janick. p. 246-251.

Rajcan I. \& M., Tollenaar. 1999. Source:sink ratio and leaf senescence in maize: I. Dry matter accumulation and partitioning during grain filling. Field Crop Reserch. 60: 245253

Rimieri, P.; J. R., Carrete y M. S., Alessandro. 2001. Degradabilidad in situ de la materia seca de dos estratos del tallo de maíz. $24^{\circ}$ Congreso Argentino de Producción animal. Revista Argentina de Producción Animal. Vol. 21, Supl. 1:21-22.

Ritchie, S. \& J. J., Hanway. 1982. How a corn plant develops. Iowa State Univ. Technol. Spec. Rep., 48 p.

Romero, L. y S., Aronna. 2004. Siembra de maíz para silaje. Proyecto Regional de Lechería. INTA. EEA Rafaela. 
Roth, L. S.; G. C., Marten; W. A., Compton \&, D. D., Stutman. 1970. Genetic variation of quality traits in maize (Zea mays L.) forage. Crop Science., 10 (5), 365-367.

Sadras, V. O.; Echarte, L. \&, Andrade, F. H. 2000. Profiles of leaf senescence during reproductive growth of sunflower and maize. Annals of Botany. 85:187-195.

SAGPyA. 2011. Producción de maíz 2011. Secretaría de Agricultura, Ganadería, Pesca y Alimentación. Dirección de Agricultura. Buenos Aires, Argentina.

SAS Institute. 2010. SAS/SAT user’s guide. Version 9.2. SAS Inst., Cary, Inc.

Satter, L. D.; V., Moreira; H., Santos; Z., Wu \&, F., Kanitz. 2000. Relative feeding value of diverse corn silage hybrids. Pag. 31-46 in Proc. of UW Arlington Dairy Day. Arlington, WI.

Schneiter, O. y J. R., Carrete. 2004. Aspectos agronómicos del maíz para silaje. Idia XXI. N6 Junio. Pág. 134-140.

Shaver, R. D. 2003. Practical aplication of new forage quality tests. Departament of Dairy Sciances. University of Wisconsin-Madison.

Struik, P.C. and B. Deinum. 1990. The ideotype for forage maize (whit special reference to nutritive value). Department of Field Crops and Grassland Science, Wageningen Agricultural University. Wageningen, The Netherlands. J. Hinterholzer (ed). Proc. 15th Congress of the maize and sorghum. Section, Eucarpia 4-8 June. Baden Near Vienna. Austria. Page: 223-242.

Thiagarajah, M.R.; L.A., Hunt \&, J.D., Mahon. 1981. Effects of position and age on leaf photosynthesis in corn. Canadian Journal of Botany. 59:28-33

Thomas, H. \& C. Howarth. 2000. Five ways to Stay green. Journal of Experimental Botany 51: 329-337. 
Thomas, E. D. 2001. Corn Hibrids for silage: 2001 performance and Outlook for 2002. $\mathrm{N}^{\circ}$ 2004. Dairy business communication.

Tollenaar, M.; T. B. Daynard \&, R. B. Hunter. 1979. Effect of temperature on rate of leaf appearence and flowering date in maize. Crop Science. 19:363-366.

Tollenaar, M. \& T. B. Daynard. 1982. Effect of source-sink ratio on dry matter accumulation and leaf senescence of maize. Canadian Journal Plant Science. 62, 855860.

Tollenaar, M.; S. P. Nissanka; I. Rajcan \&, T. W. Bruulsema. 1997. Yield response of old and new corn hybrids to nitrogen. Better Crops. Vol. 81, No. 4.

Twumasi-Afriye, S. \& R. B., Hunter. 1982. Evaluation of quantitative methods for determining stalk quality in short-season corn genotypes. Canadian Journal Plant Science. 62:55-60.

Uhart, S. A. \& F. H. Andrade. 1995. Nitrogen and Carbon Accumulation and Remobilization during Grain Filling in Maize under Different Source/Sink Ratios. Crop Science. 35:183-190.

Valentinuz, O. R. \& M. Tollenaar. 2004. Vertical profile of leaf senescence during the grain-filling period in older and newer maize hybrids. Crop Science. 44:827-834.

Van Olphen, P. V. ; E. M. Viviani Rossi, L. M. Gutierrez \&, F. Santini. 2000. Efecto del momento y altura de corte sobre la producción y calidad de la materia seca de maíz para silaje. XVI Reunión Latinoamericana de Producción Animal, Montevideo. Marzo 2000.

Vatikkonda, M. R. \& R. B. Hunter. 1982. Comparison of grain yield and whole plant silage production of recomended corn hybrids. Canadian Journal Plant Science. 63:601609.

Vogel, K.; J. Pedersen, S. Masterson \&, J. Toy. 1999. Evaluation of a filter bag system for NDF, and IVDMD forage analysis. Crop Science. 39:276-279. 
Wolfe, D. W.; D. W., Henderson; T. C., Hsiao \&, A., Alvino. 1988. Interactive water and nitrogen effects on senescences of maize. II. Photosynthetic decline and longevity of individual leaves. Agronomy Journal, 80:865-870.

Wu, Z. \& G., Roth. 2003. Considerations in manaing cutting height of corn silage. Departament of dairy and animal science. The Pennsylvania State University. Dairy \& Animal Science. DAS 03-72.

Zimmer, E. \& M., Wermke. 1986. Improving the nutritive value of maize. Breeding of silage maize: proceedings of the 13th Congress of the Maize and Sorghum Section of EUCARPIA, Wageningen, Netherlands, 9 - 12 September 1985. pp. 31-100. 


\section{Anexo:}

Tabla 20. Análisis de Varianza del ensayo Ambiente×Genotipo×Altura de Corte, para la variable IE.

\begin{tabular}{llllll}
\hline FV & GL & SC & CM & F & P(\%) \\
\hline A & 3 & 0,667575 & 0,222525 & 24,19 & $<0,01$ \\
$\mathrm{G}$ & 5 & 0,074237 & 0,014847 & 4,05 & 1,59 \\
$\mathrm{H}$ & 2 & 0,392136 & 0,196068 & 40,64 & 0,03 \\
Bloques (A) & 8 & 0,009693 & 0,001212 & 3,12 & 0,29 \\
$\mathrm{~A} * \mathrm{G}$ & 15 & 0,054994 & 0,003666 & 32,25 & $<0,01$ \\
$\mathrm{~A} * \mathrm{H}$ & 6 & 0,028945 & 0,004824 & 42,44 & $<0,01$ \\
$\mathrm{G} * \mathrm{H}$ & 10 & 0,000664 & 0,000066389 & 0,58 & 81,39 \\
$\mathrm{~A} * \mathrm{G} * \mathrm{H}$ & 30 & 0,003410 & 0,000114 & 0,29 & 99,99 \\
Error & 30 & 0,003410 & 0,000114 & & \\
\hline FV: Fuente de Variacion; GL: Grados de Libertad; SC: Sumatoria de Cuadrados; CM: Cuadrado Medio.
\end{tabular}

Tabla 21. Análisis de Varianza del ensayo AmbientexGenotipo×Altura de Corte, para la variable contenido de materia seca de planta completa.

\begin{tabular}{llllll}
\hline FV & GL & SC & CM & F & P(\%) \\
\hline Ambiente (A) & 3 & 1183,999278 & 394,666426 & 13,37 & $<0,01$ \\
Genotipo (G) & 5 & 388,069283 & 77,613857 & 2,87 & 5,15 \\
Altura (H) & 2 & 460,810758 & 230,405379 & 402,63 & $<0,01$ \\
Bloques (A) & 8 & 24,447244 & 3,055906 & 3,64 & 0,07 \\
A*G & 15 & 405,090772 & 27,006051 & 101,50 & $<0,01$ \\
A*H & 6 & 3,433486 & 0,572248 & 2,15 & 7,64 \\
G*H & 10 & 5,268675 & 0,526867 & 1,98 & 7,25 \\
A*G*H & 30 & 7,982414 & 0,266080 & 0,32 & 99,97 \\
Error & 30 & 7,982414 & 0,266080 & & \\
\hline
\end{tabular}

FV: Fuente de Variación; GL: Grados de Libertad; SC: Sumatoria de Cuadrados; CM: Cuadrado Medio. 
Tabla 22. Análisis de Varianza del ensayo Ambiente×Genotipo×Altura de Corte, para la variable digestibilidad in vitro de planta completa.

\begin{tabular}{llllll}
\hline FV & GL & SC & CM & F & P(\%) \\
\hline A & 3 & 888,766944 & 296,255648 & 2,72 & $<0,01$ \\
$\mathrm{G}$ & 5 & 521,503844 & 104,300769 & 7,01 & 0,15 \\
$\mathrm{H}$ & 2 & 1031,520208 & 515,760104 & 75,27 & $<0,01$ \\
Bloques (A) & 8 & 26,048122 & 3,256015 & 2,56 & 1,25 \\
$\mathrm{~A} * \mathrm{G}$ & 15 & 223,326589 & 14,888439 & 33,66 & $<0,01$ \\
$\mathrm{~A} * \mathrm{H}$ & 6 & 41,111158 & 6,851860 & 15,49 & $<0,01$ \\
$\mathrm{G} * \mathrm{H}$ & 10 & 2,984647 & 0,298465 & 0,67 & 73,86 \\
$\mathrm{~A} * \mathrm{G} * \mathrm{H}$ & 30 & 13,270542 & 0,442351 & 0,35 & 99,94 \\
Error & 30 & 13,270542 & 0,442351 & & \\
\hline FV: Fun & & &
\end{tabular}

FV: Fuente de Variación; GL: Grados de Libertad; SC: Sumatoria de Cuadrados; CM: Cuadrado Medio.

Tabla 23. Análisis de Varianza del ensayo AmbientexGenotipoxAltura de Corte, para la variable rendimiento en materia seca de planta completa.

\begin{tabular}{llllll}
\hline FV & GL & SC & CM & F & P(\%) \\
\hline A & 3 & 2818847645 & 939615882 & 68,09 & $<0,01$ \\
$\mathrm{G}$ & 5 & 38787460 & 7757492 & 0,83 & 54,57 \\
$\mathrm{H}$ & 2 & 277085174 & 138542587 & 570,88 & $<0,01$ \\
Bloques (A) & 8 & 46948514 & 5868564 & 3,83 & 0,04 \\
$\mathrm{~A}{ }^{*} \mathrm{G}$ & 15 & 139562972 & 9304198 & 108,90 & $<0,01$ \\
$\mathrm{~A} * \mathrm{H}$ & 6 & 1456084 & 242681 & 2,84 & 02,60 \\
$\mathrm{G} * \mathrm{H}$ & 10 & 1325993 & 132599 & 1,55 & 16,98 \\
$\mathrm{~A} * \mathrm{G} * \mathrm{H}$ & 30 & 2563121 & 85437 & 0,06 & 100,00 \\
Error & 30 & 2563121 & 85437 & & \\
\hline FV: Fuen & & &
\end{tabular}

FV: Fuente de Variación; GL: Grados de Libertad; SC: Sumatoria de Cuadrados; CM: Cuadrado Medio. 
Tabla 24. Análisis de Varianza del ensayo AmbientexGenotipoxAltura de Corte, para la variable rendimiento en materia seca digestible de planta completa.

\begin{tabular}{llllll}
\hline FV & GL & SC & CM & F & P(\%) \\
\hline A & 3 & 919690065 & 306563355 & 48,91 & $<0,01$ \\
$\mathrm{G}$ & 5 & 11910636 & 2382127 & 0,51 & 76,53 \\
$\mathrm{H}$ & 2 & 41283901 & 20641950 & 188,93 & $<0,01$ \\
Bloques (A) & 8 & 17580458 & 2197557 & 3,14 & 0,27 \\
$\mathrm{~A} * \mathrm{G}$ & 15 & 70205678 & 4680379 & 231,45 & $<0,01$ \\
$\mathrm{~A} * \mathrm{H}$ & 6 & 655560 & 109260 & 5,40 & 0,07 \\
$\mathrm{G} * \mathrm{H}$ & 10 & 317650 & 31765 & 1,57 & 16,37 \\
$\mathrm{~A} * \mathrm{G} * \mathrm{H}$ & 30 & 606665 & 20222 & 0,03 & 100,00 \\
Error & 30 & 606665 & 20222 & & \\
\hline FV: Fun & & & & &
\end{tabular}

FV: Fuente de Variación; GL: Grados de Libertad; SC: Sumatoria de Cuadrados; CM: Cuadrado Medio. 